\section{丽 Heighten Science \\ P U B L I C I T T I O N S Corporation}

ISSN

2574-0350

\title{
Cumulative Effect Assessment: preliminary evaluation for Environmental Impact Assessment procedure and for environmental damage estimation
}

\author{
Marco Ostoich ${ }^{1 *}$ and Andrea Wolf ${ }^{2}$ \\ 'Veneto Regional Prev, and Prot. Agency (ARPAV), Venice Prov. Dep, via Lissa 6, Venice, Italy \\ ${ }^{2}$ Environmental specialist pivate sector, Msc. in Environmental Science, University of Venice, \\ Ca' Foscari, Venice, Italy
}

\begin{abstract}
*Address for Correspondence: Marco Ostoich, Veneto Regional Prev, and Prot. Agency (ARPAV), Venice Prov. Dep, via Lissa 6, Venice, Italy, Email: marco.ostoich@arpa.veneto.it
\end{abstract}

Submitted: 17 August 2017

Approved: 06 October 2017

Published: 09 October 2017

Copyright: @ 2017 Ostoich M, et al. This is an open access article distributed under the Creative Commons Attribution License, which permits unrestricted use, distribution, and reproduction in any medium, provided the original work is properly cited.

Keywords: Environmental Impact Assessment (EIA); Strategic Environmental Assessment (SEA); Cumulative Effect Assessment (CEA); Reasonably Foreseeable Future Actions (RFFAs); Environmental Impact Study (EIS); Environmental Preliminary Study (EPS); Environmental Incidence Evaluation (EIE); Pressure factors; Environmental damage

\section{Abstract}

The paper presents and develops the issue of Cumulative Effect Assessment (CEA) in the Environmental Impact Assessment (EIA) screening procedure established by the State and Regional regulations In Italy. In the period 2001-15 in the territory of the Venice province (north east Italy, Veneto region) n. 328 projects (and the related environmental preliminary/definitive studies) were applied to competent Authorities (6\% to the State, $39 \%$ to the Region and $55 \%$ to the Province). All the Environmental Impact Studies (EISs) and Environmental Preliminary Studies (EPSs) referring to the this territory officially applied to competent Authorities in the period 2001-2010, have been analysed with focus on the identification and assessment of cumulative effects (CEs); the projects considered and analysed for this purpose comprise a total of $n$. 181 EIA screening and ordinary procedures; the remaining 147 projects in the period 2011-15 (for a total of 328) are here considered only for statistical reason to an update assessment of project typologies in the same territory.

The methodology applied for the analysis of the sample of environmental studies in the period 200110 refers to that presented by Cooper and Sheate (2002) with modifications. The investigation has been developed looking for the way in which the topic is performed by practitioners in the environmental studies as from qualitative as well as quantitative point of view. Specific attention has been paid to waste management plants which are always subject to EIA screening procedure since 2008 according to Directive 97/11/EEC and in case to the whole EIA procedure. The approach proposed by Lombardia Region (North Italy; 2010) for EIA screening procedure of waste management plants has been applied to identify CEs and modified according to the characteristics of the considered territory; it allows the performance of the project-based approach and must be completed with a regional-based approach (Dubè, 2003). The proposed approach can be useful in case of waste management and IPPC (Integrated Pollution Prevention and Control, Directive 96/61/EEC, amended with Directives 2008/1/EC and 2010/75/EU) plants to define the financial warranties required for the authorization of operative activity of the plants to cover potential environmental damages produced in cases of accidents and other conditions as required in Europe (art. 14 Directive 2004/35/EC on environmental liability).

Several project categories were chosen and their EISs analysed as an exemplificative case according to the potential generation of cumulative impacts and the characteristics of the territory. With reference to the completed procedures where the competent Authority presented a final judgement, it has been observed that the CEA has been seldom developed due to not compulsory legal requirements as already observed by Burris and Canter (1997). Moreover, when it is considered, the methodology is limited and not systemized. Indices of impact have been identified according to emission for the main environmental components focussed with the analysis of the pressure factors of the plants. The study points out the need to analyse and evaluate the cumulative effects (CEs) at a strategic level (within the Strategic Environmental Assessment-SEA-procedure) with a view to preparing the study for EIA/EPS framework procedure for the projects derived from the corresponding plan/program. A sound knowledge of the considered territory and in particular of its pressure sources is of main importance for CEA assessment and impacts' prevention. Geographic Information Sytesm (GIS) application is strongly needed for pressure sources' census and control data storing 


\section{Introduction}

One of the most complex problems faced by environmental impact assessment (EIA) is the accumulation in space and time of impacts produced by single or multiple projects; these impacts are called "cumulative effects" (CEs). This issue was introduced at the beginning of the '90s by authors like [1-3], and was developed by Canter [4], in the context of habitat based methods (Habitat Evaluation System-HES, Habitat Evaluation Procedure-HEP). Cumulative effects are a burning issue both scientifically and legally for different reasons. Firstly, the cumulative effects appear to be difficult to define univocally, as they sometimes encompass indirect and interacting impacts.

At the European level, the EIA procedure was regulated by Directive 85/337/EEC [5], subsequently amended by Directive 97/11/EC [6], (which introduced the screening procedure), Directive 2003/35/EC [7] and more recently by Directive 2011/92/EU [8], which repealed the first two directives and by Directive 2014/52/EU [9]. Within this context, the environment and its components are taken to be: the population, animals and vegetation, soil, water, air, the climate, material goods, architectural and archaeological estates, the landscape and the interaction between these factors. EIA is the most frequently used worldwide technical administrative tool when assessing impacts that could be generated by single interventions or projects. The USA was the precursor of EIA with the approval in 1969 of the National Policy Act [10], with the institution of the Council of Environmental Quality (CEQ) and of the Environmental Protection Agency (EPA).

The present study develops the CEs issue, focusing on projects, relative to the Venice province (North-East Italy) and of different areas of competence/responsibility (State/Region/Province according to the Italian institutional set up of the time) and for which EISs or Environmental Preliminary Studies (EPSs) had been presented in the decade 2001-2010 [11,12]. The assessment led to identification of certain projects which are significant, in terms of accumulation (in space and time) with other preexisting projects and therefore to evaluate the degree of investigation required to establish the cumulative effect in EISs and EPSs. The main and more interesting project categories from environmental point of view, identified during the statistical analysis, were: tourist harbours, large outlet structures and waste management plants. According to the identified main project typologies waste management plants have been pointed out as critical from the potential cumulative effects and environmental damages in ordinary and extraordinary conditions (accidents, fires, etc.). The study puts forward methodological procedures for CEA, based on the assessment of many real case situations and on scientific literature $[13,14]$.

The study presents the proposed issue in the legal framework at European level but the approach can be easily transposed to other contexts in a generalized way. The paper analyses as case study the territory of the province of Venice (Veneto region, northeast Italy, figure 1): in the period 2001-10 n. 181 projects and the related EISs/EPSs: have been presented to the competent authorities (State, Region, Province) according to the project typology. The environmental studies (preliminary and definitive) have been in-depth assessed to understand how and to which extent the CEs have been considered. Moreover, for completeness, the projects and the related environmental studies (preliminary/definitive) presented to competent Authorities in the same territory in the period 2011-15 have been investigated in order to present an outlook of the project typologies applied at the different decisional levels in this sensitive and critical area: n. 147 projects have been applied, of which 6 refer to State competence, 58 to regional competence and 83 to provincial competence. These last data have been considered only from statistical point of view (the corresponding environmental studies - preliminary as well as definitive - have not been analysed in detail). The total number of environmental studies (and the related projects) presented in the whole period 2001-15 is 328, of which 19 of State competence, 127 of regional competence and 182 of provincial competence. 


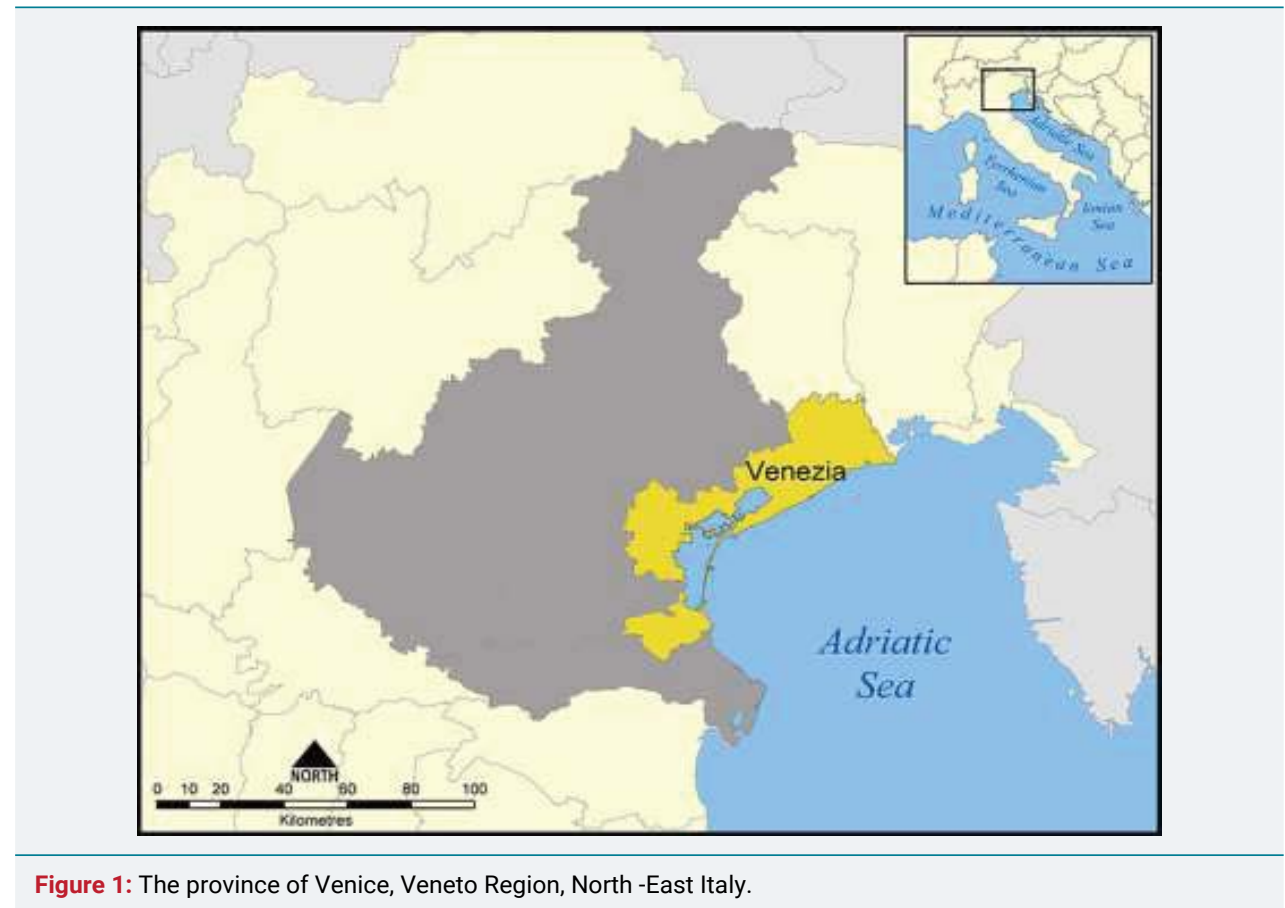

From the performed statistical analysis, based on available data referring to the studies under consideration (EIS and EPS) in the period 2001-10, some important observations have been obtained. Despite their importance, CEs are seldom studied in the analysed projects' set with the same level of accuracy as that applied to direct impacts; if the number of EISs and EPSs where CEs are not indicated is only $5(22 \%)$, then other studies define the area of the proposal's impact to a periphery which is limited to within just a few meters around the proposed site. The $41 \%$ of the studies carried out conclude that CEs are absent or are considered to be insignificant, without giving any assessment or giving an extremely sketchy assessment; $36 \%$ of the studies only mention CEs in the incidence assessment procedure (EIE) according to Directive 92/43/EEC [15], (Habitat directive).

This study proposes a methodological approach for the assessment of the CEs for waste management projects/proposals according to experience and EIS/EPS analysed; this approach would help the members of the regional and provincial EIA technical commissions to better understand whether or not CEs have been assessed correctly, satisfactorily and if they could be helpful in supporting private practitioners involved in the preparation of EISs and EPSs. For this purpose, the study applies with modifications the procedure elaborated by the Lombardia Region (Northern Italy, 2010) for waste management plants, based on the local situation in the Veneto Region. In this proposal, Geographic Information Systems (GIS) have a primary role in the identification and assessment of CEs [16]. The procedure is set for EIA screening and requires the knowledge of pressure sources, their emissions, the general environmental quality and GIS support. The proposed approach, derived from the practical analysis of projects from EIA screening and ordinary procedure, is founded on regional based CEA [38] and appears as a supporting decisional tool for environmental and spatial planning. Moreover the approach appears useful for the identification and estimation of potential environmental damages tied to operative activity of the proposed plant (in particular for waste management and IPPC plants-Directive 2010/75/EC) [17] in ordinary and extraordinary conditions like accidents to define the financial warranties required by art. 14 of Directive 2004/35/EC [18] on environmental liability. In the present study it is assumed that the ecological evaluation for naturally important areas is performed in the Environmental Incidence Evaluation (EIE) procedure. Due to art. 4 of Directive 2011/92/EU [8], the decision if a project/intervention has to follow an 
EIA assessment is determined by a case-by-case approach or by the criteria defined in Annex III to the Directive. Annex III within the project's characteristics considers the accumulation of impacts with other projects too. The proposed methodological path appears adequately flexible and useful to satisfy this requirement. CEA is an essential tool for sound environmental and spatial planning as required by Directive 2014/52/EU, which modified Directive 2011/92/EU. It is evident that an effort should be done to build a comprehensive environmental data storage and apply GIS to create an updated data-base on pressure sources in order to allow public administrations and practitioners in performing appropriate environmental assessment, with CEA included, in EIA and ESP procedure.

\section{Environmental preventive assessment procedures in European context}

The decision process can be reduced down to three levels: policies, plans/ programmes and projects (PPP). The environmental preventive evaluation procedures in Italy refer to SEA [54], for the planning level, to EIA for projects and programmes, to Integrated Environmental Authorization for the operative level (IPPC Integrated Pollution Prevention and Control Directive 2010/75/EC [17]) and to environmental management systems at the voluntary level (EMAS Environmental Management and Audit Scheme-Regulation n. 761/2001, ISO 14000/2004 [19,20]. All these tools derive from specific regulations established by the EU and which were transposed into the Italian legal framework with Italian Decree n. 152/2006 [45], part II. EIA and SEA should be complementary in a "tiering approach". SEA can significantly reduce the assessment work at the lower assessment levels. The Canadian Environmental Assessment Agency [22] pointed out that one of the biggest shortcomings in the application of SEA is the lack of a structured methodological framework which could pinpoint the needs of the SEA itself. The existing relationship between EIA and SEA depends on how detailed the latter is, as this would highlight which decision making aspects of the projects should be left to the EIA procedure.

\section{Cumulative Effect Assessment (CEA)}

Referring to the definition introduced by the US-CEQ [21], Hegmann et al. [22], explained cumulative effects as: "an effect on the environment that results from the incremental, accumulating and interacting impacts of an action when added to other past, present, and reasonably foreseeable future actions" (RFFAs). In particular, the US-CEQ [21] observed that "cumulative impacts can result from individually minor but collectively significant actions taking place over a period of time". Scientific literature highlights the existing debate regarding which assessment tools are the most appropriate when studying CEs [23]. The issue of "future actions" in CEA, which distinguishes between a "probable future event" and purely "speculative" actions, was introduced and discussed by Rumrill and Canter [24]. CEA is essential to the development of appropriate management strategies when dealing with the environmental consequences of human activities [25]. Burris and Canter [26] observed, by means of a case study, that CEs are much more developed when there is a specific requirement in the regulation in force.

The domain of interest of CEs generally has broader spatial and temporal boundaries than those of direct impacts. They not only concentrate on a single project which is subjected to EIA but also aim to give a general overview of what is happening in the neighbouring territory; the impacts generated by other human interventions which are already present in the territory must be taken into consideration and assessed too. CEA is a process that aims to forecast the consequences of development by referring to and evaluating existing quality data.

Theoretically, CEA allows for an on-going mechanism to assess whether or not the designed development levels exceed the assimilative or carrying capacity of the environment being considered and therefore its self-sustaining capacity. CEA 
methods used to identify cumulative impacts include: professional advice, matrices, public consultations, qualitative descriptions, modelling methods (for identifying and forecasting impacts), visibility maps, overlay maps. The significant impact assessment is based on the following main factors: impact intensity; spatial extension; durable effects and frequency of the impact; sensitivity of the receptor. According to Cooper and Shate [14], the tendency to consider and analyze the CEs is followed: in studies for which scoping has been required; in studies for interventions concerning environments influenced by the application of the Habitat Directive; according to the indications of the competent Authority.

CEA is a very complex procedure at both theoretical and practical levels. Variables to be considered are multiple and there is still not enough clarity concerning the methodologies to be used or the competences of the public and private sectors. At the international level many studies describe the difficulty in the application of CEA [14,27-29]. CEA, in fact, can be performed at both the project and strategic levels. The initial assesment at the strategic level, is that required by the SEA. The second is typical of the EIA and is characterized by the environmental impact study (EIS) when the proposer evaluates if the project can generate CEs during interaction with other projects which are already present or foreseeable in the considered territory. Should this be the case, the public Authority (State, Region or Province) must ensure that all cumulative environmental impacts are carefully assessed and confronted right from the early stages of the planning process with their own plans and programmes, or before the single projects are proposed.

The SEA concept has been greatly improved and closely linked to the achievement of sustainable practices and to the consideration of CEs. This was soon seen to be a way of supplying an adequate context and a logical base for sound integrated induced, synergic and long-term effects. Partidario [30], observes that SEA must be "tailor made" according to the type of decision and the nature of the decision process being considered. Therefore SEA requires highly adaptable and flexible decisions as it has to deal with a wide spectrum of forces, which exists and operates at many different levels and in diverse contexts, where social values vary and high uncertainty levels are expected with regard to the outcomes [31]. Cooper and Shate [14] observe, in particular, that the absence of a univocal definition of CEA and of precise, straight forward guidelines produce limiting factors for the sound application of CEA; they also observe that, where scoping is developed and CEA is required, the CEs have consequently been assessed.

At European level Directive 97/11/EC [6], on EIA procedure establishes scoping requirements (albeit non-compulsory) which can draw attention to the CEs. Cooper and Shate [14], observe a general inadequacy of the guidelines, where they actually exist [22,32-34]. According to the definition for CEA by Hegmann et al., [22], a very general approach with high range for CEs is assumed; consequently in the EC guide-line [34] three categories of impacts have been integrated: 1) direct impacts; 2) cumulative impacts; 3) interactions of impacts. The identification and assessment of CEs appears to be a very sensitive operation and to a certain degree arbitrary. If the direct impacts of a project can normally be predicted with a relatively low degree of uncertainty, this is not always true for CEs. Sometimes it is necessary to establish the hypothesis on which the assessment must be founded. Bearing this in mind, the main aspect is that the author/s of the EIS/EPS must clearly present the hypothesis considered [34].

The US-CEQ (US Council of Environmental Quality) definition of CEs [21], states that they are incremental impacts of the action when added to other past, present and reasonably foreseeable future actions (RFFAs). The main problem is the determination of what activities should be considered to be RFFAs. When not resolved by the proposer and/or Authorities, the question should be discussed in the Courts. From Court rulings 
it is evident that only formal proposals are to be considered in RFFAs. The Courts decide if an action is a "probable future event" or a merely "speculative" one. Therefore, informal proposals are considered as "reasonably foreseeable and speculative" [24]. CEA is required in particular for probable (reasonably foreseeable) future events and connected actions. Specific connections include: proposal intent, geographic connections and planning relationships. As for other types of environmental impacts, specific tools are necessary to identify and assess CEs. Essentially, two different approaches are possible in a CEA: the analytic approach and the planning approach [14].

GIS, landscape analysis and simulation modelling are considered to be highly useful methods of CEA. The structure of the generative process of CEs follows a causal scheme: sources, paths, effects on the environmental components. The choice of the assessment methods of the CEs considers the following assessment criteria: 1) temporal accumulation (time scale and frequency of the phenomenon); 2) spatial accumulation; 3) type of perturbation; 4) accumulation process; 5) functional effects; 6) structural effects. GIS appears necessary for the assessment and management of CEs, as observed by Atkinson and Canter [16], and for the achievement of environmental sustainability. The latter is conditioned by direct and indirect effects from single projects but also by the CEs of multiple, planned actions when coupled with similar effects from other past, present and future actions. Therefore CEA can supply a positive contribution to environmental sustainability [35] by applying GIS particularly where conflicting interests can be observed between human needs and conservation objectives [36].

Atkinson and Canter [16], investigated the use of GIS in developing CEA and analysed the final Court rulings in litigations when GIS had been used for CEA. GIS appears very useful in CEA due to the need to analyze large, complex and geographically referenced data sets (spatial and temporal data). GIS allows for the use of multiple layers (historical and current environmental information); new environmental information can be added over time and space; it is particularly useful in evaluating planning options. Data base construction is an important and sensitive phase; GIS can be used as a tool in follow-on impact monitoring, project management and adaptive management. In general, GIS can enhance data management, data overlay analysis, cumulative effects analysis, trend analysis, dispersion models and Habitat Evaluation Processes [16]. Specific indicators must be selected and used in the assessment process for VECs (Valuable Ecosystem Components as defined by [16]; US Federal Courts consider GIS to be an acceptable tool for CEA; in particular the ability of GIS to perform spatial analysis and numerical modelling has been highlighted [16].

To describe the baseline conditions and predict the cumulative consequences of multiple actions, environmental indicators and multi-metric indices are used. Historical as well as current baseline conditions can be assessed with specific indicators/indices [37]; these Authors identify some main categories: sustainability or sustainable development indicators, ecological indicators, social and economic indicators for transportation projects, multiple valued ecosystem components (VEC), regional indicators/indices, landscape indicators for aquatic impacts. Pressure/stress indicators/indices are representative of VEC studies; they reflect historical and current pressures on aquatic ecosystems. This approach permits the identification of three conservation priority categories (high, intermediate and low) for cumulative effects' management.

Burris and Canter [26], observed that scoping is a useful exercise for identifying and assessing potential CEs and professional judgement plays a critical role in determining the significance of impacts. In the analysis/investigation of CEs the following needs were pointed out: the definition of spatial and temporal boundaries; the definition of the process of accumulation of effects (additive, synergistic, interactive); the definition of mitigation and monitoring programs; standardized tools with methodologies and guidelines. 
The most useful methods perceived were: professional judgment; impact evaluation; case studies. With regard to resource management, CEA appears to be a useful analytical tool that can aid both the assessment process and judicial processes, but cannot substitute political objectives, such as social goals, that must always be clarified when using resources (see, for example, energy source exploitation). CEA can help to evaluate the significance of the effects of the proposed project. The assessment criterion is that the "public interest" must be secured and defined at a higher decision level, associated with political strategies and therefore it is not defined through CEA. Project analysis should be carried out on a regional scale for CEA. Spatial and temporal boundaries are of primary importance: the larger they are, the more uncertain the conclusions regarding the effects. CEA may contribute towards defining and improving the planning and regulatory framework [36].

\section{CEA project-based and regional-based approaches}

Conceptually CEA represents a possible mechanism through which the aims of sustainable development could be achieved but it remains a methodological challenge as the methods based on the induced effects (effect-based, E-B) and those based on "pressure generator" (stressor-based, S-B) are not able to be useful for the analysis when they are used in an isolated way. More deeply, as pointed out by Dubé [38], the E-B methods compare the present condition of the environment with a reference condition; the stressor-based methods, instead, foresee the positive or negative effect of a new human initiative (project) in comparison to the present state of the considered environment. The S-B approach allows foreseeing the "future state", following a new development, starting from the existing condition, while the effect-based allows assessing the cumulative state ("existing state") starting from the reference condition.

The E-B methods' predictive capacity is short as they are retrospective, that is the driving force/stressor which caused the effect is identified after the effect has been measured. If S-B and E-B methods are used singularly they do not allow defining the CEA in the context of sustainable development. In rivers, when there is pollution, a typical case of multiple pressure sources can be identified; this is an evident case of cumulative effects.

CEA requires time and spatial boundaries larger than those used in the evaluations referred to a single project (project-based approach) as the effects can appear also very far from the project in time as well as in spatial terms. Therefore a regional approach allows overtaking this obstacle: from the two concepts already discussed, to define a complete approach, it is necessary to go from the project-CEA (project-based) to the regional-CEA (regional-based).

Dubé [38], developed a methodological approach for the CEA applied to water bodies. This approach points out that the CEA at project level (project-based CEA) contributes in an active way to the CE analysis at regional level (regional-based CEA) through the following aspects:

- Effect-based evaluation, using existing local studies on environmental monitoring;

- Stressor-based evaluation of possible impacts produced by the considered project;

- Effect-based monitoring, necessary to update the existing studies on environmental monitoring.

It is of main importance, therefore, to obtain relevant in-field data, gathered locally through monitoring programmes, which must be adequately designed. The E-B assessment is implemented using the local monitoring studies on environmental 
effects; it is probable that significant advance in environmental management can be achieved if the conceptual and methodological relationships between sustainable development, reports on the state of environment and CEA can be well established and systemized.

Dubè [38] indicates that the CEA process must be supported with data gathered, managed and assessed in a conformal way for the considered specific problem (that is scientifically valid data according to sector disciplinary approach). When data are produced by different Authorities and/or by different monitoring programmes, this produces a fragmentation, lack of uniformity and a limited access to the same data.

\section{Characteristics of the territory studied}

The province of Venice lies in the Veneto region (Northern Italy). With a surface of $2,462.75 \mathrm{~m}^{2}$ [39] and a population of 854,275 in 2016, the province has an extensive plain with some areas lying below sea level where water drainage is mechanical. Due to the existing communication infrastructures (train lines and highways), development is mostly East-West; the largest urban centres are: the agglomerations of Venice-Mestre, followed by Chioggia, San Donà di Piave, Mira, Mirano, Portogruaro and other minor centres [39]. The province borders with the neighbouring provinces of Padua, Treviso, Pordenone and Udine; it also encompasses the longest stretch of sea coast along the Northern Adriatic in Veneto region. The concentration of tourists is high due to the presence of the sea and of the city of Venice. Although numbers of tourists reach their peaks in the summer months, their presence remains high during the rest of the year too. The territory of the Province presents characteristics which are linked to the geographical and historical-urban driving forces. It is a plain through which flow the final stretches of several medium-large sized rivers, which originally flowed into lagoons and ponds along the coastal line (nearly $100 \mathrm{~km}$ in length). The territory derives from the alluvial deposits of the main rivers (Tagliamento, Livenza, Piave, Sile, Brenta and Adige); much of the soil derives from reclaimed lagoons and ponds and there are also pre-established and more recently formed coastal dunes [39-41]; figure 1 traces the boundaries for the Province.

\section{Materials and Methods}

\section{Preliminary assessment of cumulative effects in EIA screening procedure}

This part presents and discusses a proposal of a preliminary assessment procedure, usable by project proposers as well as by expert members of official EIA Commissions (as established in Italian National and Regional assessment processes) when assessing CEs. The aim of the procedure is to identify and perform a preliminary assessment of how much the project being considered would contribute in terms of CEs. The methodology applied for the analysis of the Environmental Impact Studies' sample refers to that presented by Cooper and Sheate [14] , for the CEA process and to the eight steps method for CEA proposed by Rumrill and Canter [25], integrated with the regional based CEA procedure proposed by Dubè [38]. The analytic path proceeds by focusing on the following aspects: concepts of CEs; scoping (topic definition in environmental studies) and baseline conditions; identification, estimation and assessment of impacts (RFFAs); impacts' management, mitigation and monitoring.

This method was designed by processing information contained in consulted and cited bibliographic materials, and considers the issues that arose in the evaluation of case studies; the methodology developed by the Lombardia Region [42], was also integrated. This last approach was developed for the EIA screening procedure for waste management plants, but it contains interesting elements potentially extendable to other types of projects, particularly with regard to the analysis of territorial and pressure sources. 
The basic assumption is that the insertion or modification of a potentially impacting element (stressor) determines a set of effects which must be characterized by increasing degrees of detail in a "tiering approach". The analytic process is performed with a conservative path to ensure that important elements are not forgotten or undermined. From the theoretical point of view, we assume that the highest number of CEs a project can produce derives from its operative phase. The functional language of the methodology is algebraic and aims to analyze case studies which are quite different one from the other. The diversity of impact studies (EISs and EPSs) with regard to analytical details, does not depend on different impact conditions as far as extension, typology or localization of the projects are concerned. This aspect determines the practical problems that ought to emerge during the analysis of the various authorization applications. It also poses important deontological issues by over-representing the real criticality concerning how socially acceptable the decisions reached during the authorization process actually are [42]. This methodology does, however, allow for a preliminary assessment of CEs.

Optimal conditions for tackling this issue will probably be achieved when a homogeneous, exhaustive mapping of the Italian territory is made available by applying appropriate anthropogenic pressure indicators for the various environmental components present. This way the proposer and the competent Authority can access precise information concerning the criticalities of a specific territory and can put together reliable quantitative tools which help to foresee any adjustments that may need to be made to a project at different space and time scales. A Geographic Information System (GIS) database is under construction by the Italian National Environmental Protection Agency [43] together with regional and provincial environmental Agencies; the project is called "Nature map" and concerns the realization of an inhabitants map on different scales: 1:250,000, 1:100,000,1:10,000. This last scale is, perhaps, the most interesting; it can integrate various assessments such as ecological value, ecological sensitivity, human pressure and the environmental fragility of mapped bio-topes through the use of significant indicators [43]. GIS appears useful for establishing the spatial and temporal boundaries of an action [16] and analyzing its interactions with ecosystems. At present this study has focused only on small and defined areas of the Italian territory and of particular ecological and environmental interest identified by the local authorities. If this tool were to be applied at local, regional and national levels, it would be a significant step forward in EIA practices and especially for SEA.

The main elements of the proposed assessment methodology are detailed as follows:

1. Stressor elements: each physical, chemical or biological entity can induce an adverse reaction [44]; in a broad sense it identifies every entity that interacts with the environmental system as human pressure. The stressor is a vector, defined as follows:

$\vec{m}_{i}=\sum_{j} a_{i j}(r, t) \hat{u}_{j}$

Where:

$\mathbf{m}_{\mathrm{i}}$ : is the $\mathrm{i}$-th stressor element, or the $\mathrm{i}$-th anthropogenic considered project;

$\mathbf{u}_{\mathrm{i}}$ : is the anthropogenic pressure indicator (for traffic source: particulate matter$\mathrm{PM}_{10}, \mathrm{CO}, \mathrm{CO}_{2}$, etc.; for details see Table 1);

$\mathbf{a}_{\mathrm{i}, \mathrm{j}}(\mathbf{r}, \mathbf{t})$ : is the anthropogenic pressure function based on time and space applied to the pressure indicator $u_{j}$

2. New stressor element $\mathrm{m}_{\mathrm{NEW}}$ i it represents the project for which an EIS is prepared and applied to the competent Authority. 
Table 1: Typologies and characteristics of the anthropogenic pressure indicators (Lombardia Region, 2010, modified).

\begin{tabular}{|c|c|c|}
\hline Indicator code & Anthropogenic pressure indicator & Typology \\
\hline $\mathrm{I}_{\mathrm{C}^{\prime} \text { PM10 }}$ & Thin dust emissions $<10 \mu \mathrm{m}\left(\mathrm{PM}_{10}\right)$ & Gaseous/Solid \\
\hline$I_{c^{\prime} \text { Nox }}$ & Nitrogen oxides emissions $\left(\mathrm{NO}_{\mathrm{x}}\right)$ & Gaseous \\
\hline$I_{c^{\prime}}$ so2 & Sulphur dioxide emissions $\left(\mathrm{SO}_{2}\right)$ & Gaseosus \\
\hline $\mathrm{I}_{\mathrm{c}, \mathrm{co}}$ & Carbon monoxide emissions (CO) & Gaseosus \\
\hline $\mathrm{I}_{\mathrm{c}, \mathrm{CO} 2}$ & Carbon dioxide emissions $\left(\mathrm{CO}_{2}\right)$ & Gaseosus \\
\hline$I_{c, \text { voc }}$ & Volatile Organic Compounds emissions (VOC) & Gaseous \\
\hline $\mathrm{I}_{\mathrm{c}, \mathrm{CH} 4}$ & Methane emissions $\left(\mathrm{CH}_{4}\right)$ & Gaseous \\
\hline $\mathrm{I}_{\mathrm{c}, \mathrm{NH} 3}$ & Ammonia emissions $\left(\mathrm{NH}_{3}\right)$ & Gaseous \\
\hline$I_{c, N 2 O}$ & Nitrogen protoxide emissions $\left(\mathrm{N}_{2} \mathrm{O}\right)$ & Gaseous \\
\hline $\mathrm{I}_{\mathrm{c}, \mathrm{ODOR}}$ & Odor emissions & Gaseous \\
\hline $\mathrm{I}_{\mathrm{c}, \text { Dissolved } 02}$ & $\begin{array}{c}\begin{array}{c}\text { Modification of the parameter relative to } \mathrm{O}_{2} \text { dissolved in the case of wastewater } \\
\text { discharge }\end{array}\end{array}$ & Liquid \\
\hline $\mathrm{I}_{\mathrm{c}, \text { BOD5 }}$ & $\begin{array}{l}\text { Modification of the parameter relative to } \mathrm{BOD}_{5} \text { assumed as indirect measure of the } \\
\text { biodegradable organic load in the case of wastewater discharge. }\end{array}$ & Liquid \\
\hline$I_{c, C O D}$ & $\begin{array}{c}\text { Modification of the parameter relative to COD assumed as indirect measure of the total } \\
\text { polluting organic load in the case of wastewater discharge. }\end{array}$ & Liquid \\
\hline $\mathrm{I}_{\mathrm{c}, \mathrm{N}-\mathrm{NH} 4}$ & $\begin{array}{l}\text { Modification of the parameter relative to Ammonia expressed as ammonium ion in the } \\
\text { case of wastewater discharge. }\end{array}$ & Liquid \\
\hline $\mathrm{I}_{\mathrm{c}, \mathrm{N} \text {-No3 }}$ & $\begin{array}{l}\text { Modification of the parameter relative to the concentration of Nitric Nitrogen, that is the } \\
\text { most oxidised form in the case of wastewater discharge. }\end{array}$ & Liquid \\
\hline $\mathrm{I}_{\mathrm{c} \text { Ртот }}$ & $\begin{array}{c}\begin{array}{c}\text { Modification of the parameter relative to Total Phosphorous in the case of wastewater } \\
\text { discharge. }\end{array}\end{array}$ & Liquid/Solid \\
\hline $\mathrm{I}_{\mathrm{C}, \text { ORGANIC POLLUTANTS }}$ & Emission of organic pollutants in the case of wastewater discharge. & Liquid/Solid \\
\hline$I_{c, \text { INORGANIC POLLUTANTS }}$ & Emission of non organic pollutants in the case of wastewater discharge. & Liquid/Solid \\
\hline $\mathrm{I}_{\mathrm{c}, \text { NOISE }}$ & Emissions of noise & Energy \\
\hline $\mathrm{I}_{\text {c,VIIBRATIONS }}$ & Emissions of vibrations & Energy \\
\hline$I_{c, \text { NON IONIIING RADIATIONS }}$ & Emissions of non ionizing radiations & Energy \\
\hline$I_{c, \text { INDUCED EMISSIONS }}$ & $\begin{array}{c}\text { Emissions of } \mathrm{PM}_{10}, \mathrm{NO}_{x^{\prime}} \text { Benzene, Toluene, Xilene, VOCs, etc., deriving from the vehicles } \\
\text { entering and exiting the project site. }\end{array}$ & Gaseous \\
\hline$I_{c, \text { soll }}$ & Change of the morphologic characters, of the consumptions and rainproof of the soil & \\
\hline $\mathrm{I}_{\mathrm{c}, \text { TRAFFIC }}$ & $\begin{array}{l}\text { Traffic and overcrowding of vehicles deriving from the project activities; all the engine } \\
\text { vehicles are encompassed (boats too) entering into and exiting from the project site, } \\
\text { whoever is the physical or juridical person owing the vehicle. }\end{array}$ & \\
\hline$I_{c, \text { GROUNDWATER }}$ & Groundwater withdrawal & \\
\hline
\end{tabular}

3. Stressor typology $\mathrm{M}_{\mathrm{Fi}}$ : it identifies a stressor class or projects with the same cluster of anthropogenic pressure indicators $u_{j}$.

4. Stressor matrix: the human pressure indicators $\mathrm{u}_{\mathrm{j}}$ are reported in columns, while the stressor elements $m_{i}$, are reported in the rows, characterized with their own pressure functions $\mathrm{a}_{\mathrm{i}, \mathrm{j}}$; for example the matrix can be:

\begin{tabular}{|c|c|c|}
\hline & $\mathbf{P M}_{10}$ emissions $\left(\mathbf{u}_{\mathbf{P M} 10}\right)$ & Noise $\left(\mathbf{u}_{\text {Rumore }}\right)$ \\
\hline $\mathrm{m}_{1}$ & $\mathrm{a}_{11}$ & $\mathrm{a}_{12}$ \\
\hline $\mathrm{m}_{2}$ & $\mathrm{a}_{21}$ & $\mathrm{a}_{22}$ \\
\hline $\mathrm{m}_{3}$ & $\mathrm{a}_{31}$ & $\mathrm{a}_{32}$ \\
\hline
\end{tabular}

5. Vulnerability elements $\mathrm{k}_{\mathrm{i}}$ : every geo-referred environmental element, characterized with defined homogeneous properties and answer capabilities to anthropogenic pressure elements $u_{i}$.

\section{Stressor characterization vector $\mathrm{A}_{\mathrm{i}}$ :}

$\mathrm{A}_{\mathrm{j}}=\alpha^{*} \mathrm{u}_{\text {Frame Specific } \mathrm{j}}$

where:

$\alpha=$ multiplicative coefficient; it is specific for the stressor typology and for the distance of the new project from the others;

$\mathrm{u}_{\text {Frame Specific } j}$ : it is the anthropogenic pressure indicator $\left(\mathrm{PM}_{10}, \mathrm{CO}, \mathrm{CO}_{2^{2}}\right.$, etc. $)$ standardized for the project typology. 
7. Specific cumulative index $\mathrm{I}_{\mathrm{c}}$ : it allows the assessment of the cumulative effect of $\mathrm{n}$ projects/interventions present in the examined area relative to a specific indicator of anthropogenic pressure $\mathrm{u}_{\mathrm{j}}$ (for example: $\mathrm{PM}_{10}, \mathrm{CO}, \mathrm{CO}_{2}$, etc.). The matrix equation to calculate $\mathrm{I}_{\mathrm{C}}$ is:

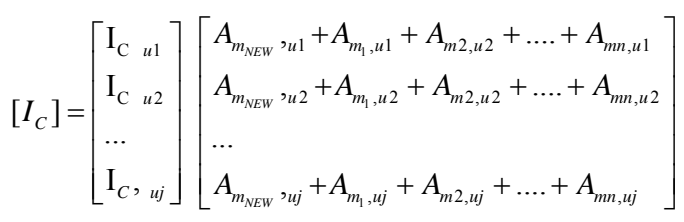

where:

$A_{\text {mNEW, Uj }}:$ is the vector which characterizes the new project $m_{\mathrm{NEW}}$ for the $j$-th anthropogenic pressure indicator.

$A_{m n, U j}:$ is the vector which characterizes the project $m_{n}$ for all the $j$-th anthropogenic pressure indicators.

\section{Whole cumulative effect index $\mathrm{I}_{\mathrm{D}}$ :}

It allows the assessment of the cumulative effect of the n-existing projects in the examined area related to all the anthropogenic pressure indicators $u_{j}$ (for traffic source: $\mathrm{PM}_{10}, \mathrm{CO}, \mathrm{CO}_{2}$, etc.).

The matrix equation to calculate $\mathrm{I}_{\mathrm{D}}$ is:

$$
\left[I_{D}\right]=\sum_{j}\left[I_{C, u j}\right]=I_{C, u 1}+I_{C, u 2}+I_{C, u 3}+\ldots+I_{C, u j}=I_{C, P M 10}+I_{C, N O x}+\ldots
$$

where:

$I_{c, u j}$ is the specific cumulative impact index relative to the $j$-th pressure indicator.

The pressure indicators $\mathbf{u}_{\mathrm{i}}$ considered in the methodology (table 1 ) have now been defined. Lombardia's (Italy) methodology has been modified with the addition of the last 4 indicators $\left(\mathrm{I}_{C}\right.$-soil; $\mathrm{I}_{C}$-traffic; $\mathrm{I}_{C}$-induced emissions; $\mathrm{I}_{\mathrm{C}}$-groundwater). We now have to define the project typologies (stressor) $\mathrm{m}_{\mathrm{i}}$ considered (table 2 , with indication of the information source). The last two project categories-tourist harbours and outlet structures-have been added to the list indicated by the Lombardia Region (North Italy) approach based on the project types selected from the project samples analyzed in the

Table 2: Typologies of projects (Lombardia Region, 2010, modified).

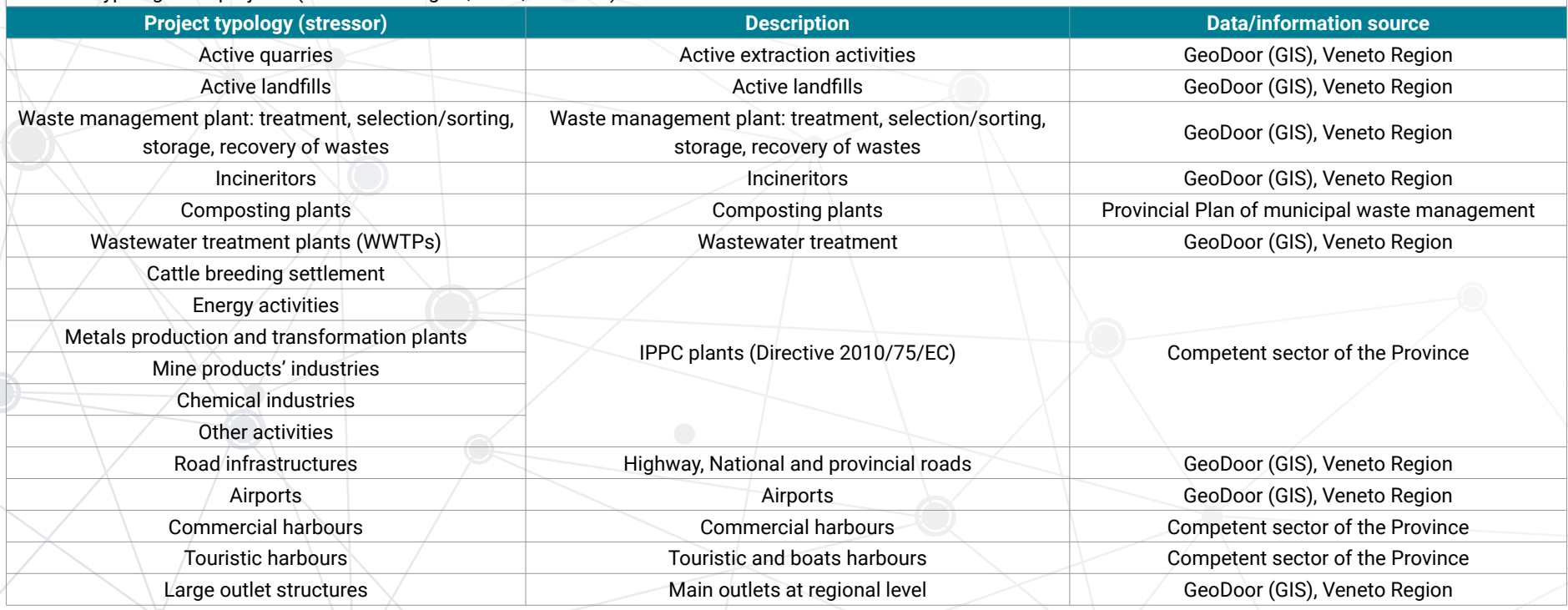


Venice Province. Applying this method calls for the geographical analysis of the context in which a new project is inserted. It is evident that the new project could generate CEs in the interaction with both existing and planned projects. The Lombardia region's approach attributes different weights to the other projects (existing or designed) during the calculation phase of the indices according to their distance from the studied project/intervention. The distance ranges are: 0-500 $\mathrm{m}$ (area 1); 500-1000 m (area 2) and 1000-1500 m (area 3).

\section{Results and Discussion}

\section{Analysis of environmental studies from EIA procedure}

In the territory of the Venice province in the period 2001-15 n. 328 environmental studies (preliminary or definitive) have been presented to competent Authorities (of which 19 to the State, 127 to the Veneto Region and 182 to the Venice Province). The project typologies that have been registered in this period in the territory of the Venice province are the following: 1) waste management plants, 2) outlets, 3) touristic settlements/ports, 4) rail and road/highway infrastructures, 5) hydraulic defense infrastructures/agricultural irrigation, 6) energy/electricity production, 7) gas pipelines and electricity transportation lines, 8) metals production/transformation industry, 9) chemical industry, 10) agro-food industry, 11) wastewater treatment facilities, 12) sludge treatment facilities, 13) breeding hens farms, 14) port urban plans, 15) vehicles parking areas, 16) querries (gravel, sand, other materials), 17) port infrastructures, 18) airport infrastructures, 19) maritime terminals and 20) other categories.

The most numerous project typologies on the period 2001-15 (with a percentage higher than 4\%) are in order of decreasing percentage the following: waste management plants with 96 projects $(29,3 \%)$, hydraulic defense infrastructures/ agricultural irrigation with 51 projects $(15,5 \%)$, other categories with 40 projects $(12,2)$, outlets with 39 projects $(11,9 \%)$, energy/electricity production with 18 projects $(5,5 \%)$, touristic settlements/ports with 16 projects $(4,9 \%)$ and rail/road/ highway infrastructures with 16 projects $(4,9 \%)$.

In figure 2 the number and percentage of the project typologies submitted to competent Authorities are reported and in figure 3 the number and percentage of the project according to the competent Authority in the period 2001-15 are represented, both for the period 2001-15. In 2013 an in depth assessment of the applied EISs and EPSs to competent Authorities for the territory of the province of Venice has been performed using official documents and data available in the competent office of the Province of Venice. This study considered all the projects and related documentation submitted by applicants in the previous period since the enforcement of the regional law on environmental impact assessment. In the 2001-10 period n. 181 EIA and EIA screening procedures were activated in the Province of Venice; the projects submitted by applicants in these procedures geographically within the province boundaries and the related environmental studies (preliminary or definitive) have been analysed to understand how and to which extent the CEs have been addressed and considered by practitioners (see next §). Based on the competent Authorities established by the Regulations in force in Italy [45], these processes fall into the following categories: National, Regional and Provincial procedures. The first two categories include those projects whose competent EIA Authorities are the State or the Region respectively. The role of the Province in these cases is purely advisory and is exerted by the provincial Council. Project typologies which are strictly of Provincial competence are set out in the Veneto regional Law n. 10/1999 [46]. The Provincial EIA commission is identified as the technical structure responsible for judging the environmental compatibility and defining specific prescriptions, where appropriate. The relative percentages and the number of EIA and screening proceedings for the period 2001-10 are: 13 at national level, 69 at regional level and 99 at provincial level. This illustrates that there is an 


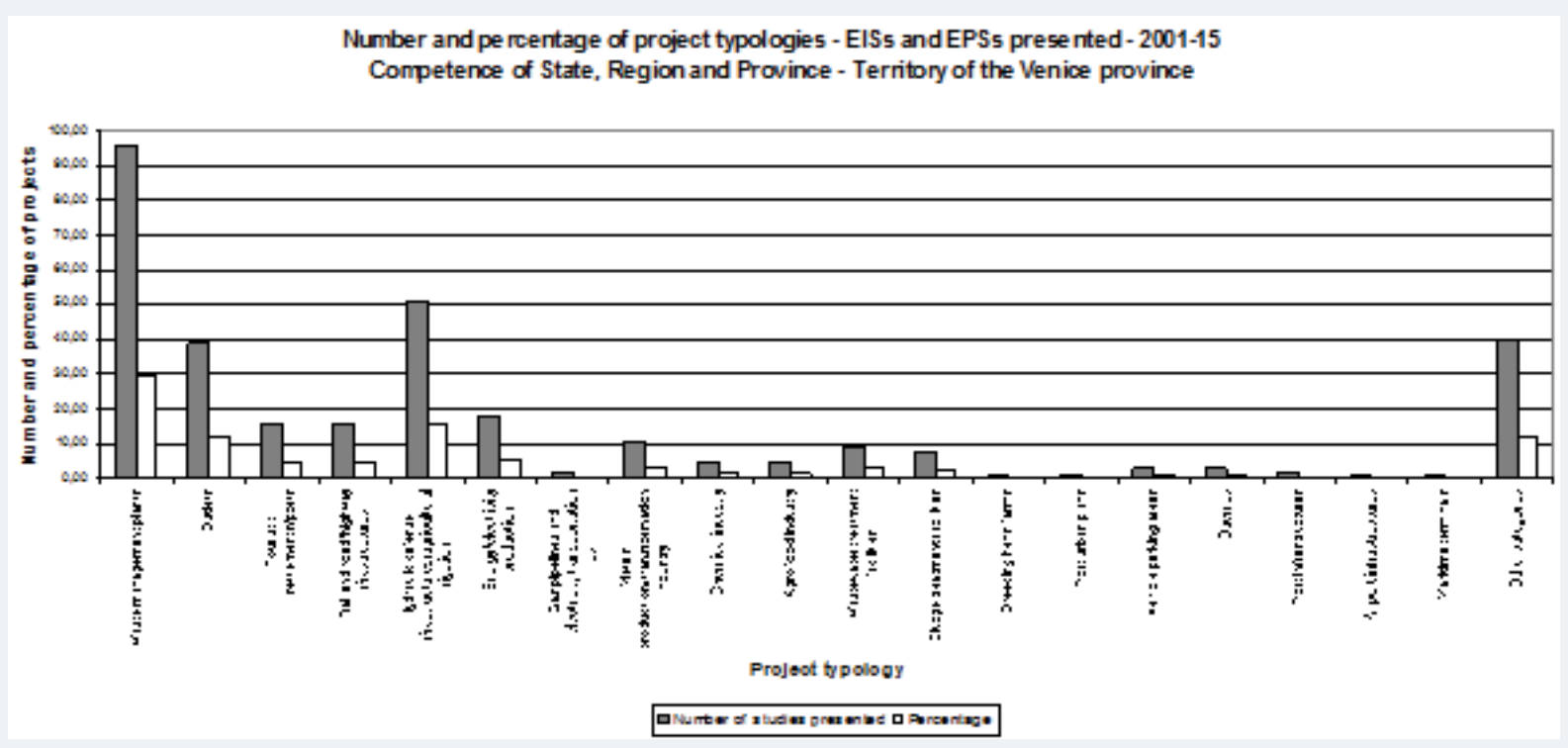

Figure 2: Project typologies-Venice province territory (north east Italy)-EIA procedure (screening and ordinary) in the period 2001-15 (Source: data from administrative proceedings Province of Venice [41])

Number and percentage of projects presented in the Venice province territory referred to competent Authority Period 2001-15

Figure 3: Number and percentage of projects under EIA procedure applied to competent Authorities in the period 2001-15-Territory of the Venice province (Source: data from administrative proceedings Province of Venice [41]).

increasing number of projects that span national to provincial competence; the relative abundance is in juxtaposition to the real, potential impact of the project considered. This aspect is somewhat intuitive if we consider that, generally speaking, the more a project is significant in terms of dimensions, production volume and economic investment, the greater the impact it can have on the environment. The number and percentage of the project typologies applied to the competent Authorities in the territory of the Venice province in the period 2001-10 are reported in figure 4. In figure 5 the number of projects applied in this period are referred to the competent Authorities.

The project categories and their related projects of national competence (State) are 13 ( 4 for rail/road infrastructures; 3 for electricity plants; 3 for chemical industry; 2 for gas pipeline/electricity transportation and 1 for harbour plan), The number of EISs presented is too limited to be used to produce relevant statistics, however, it 


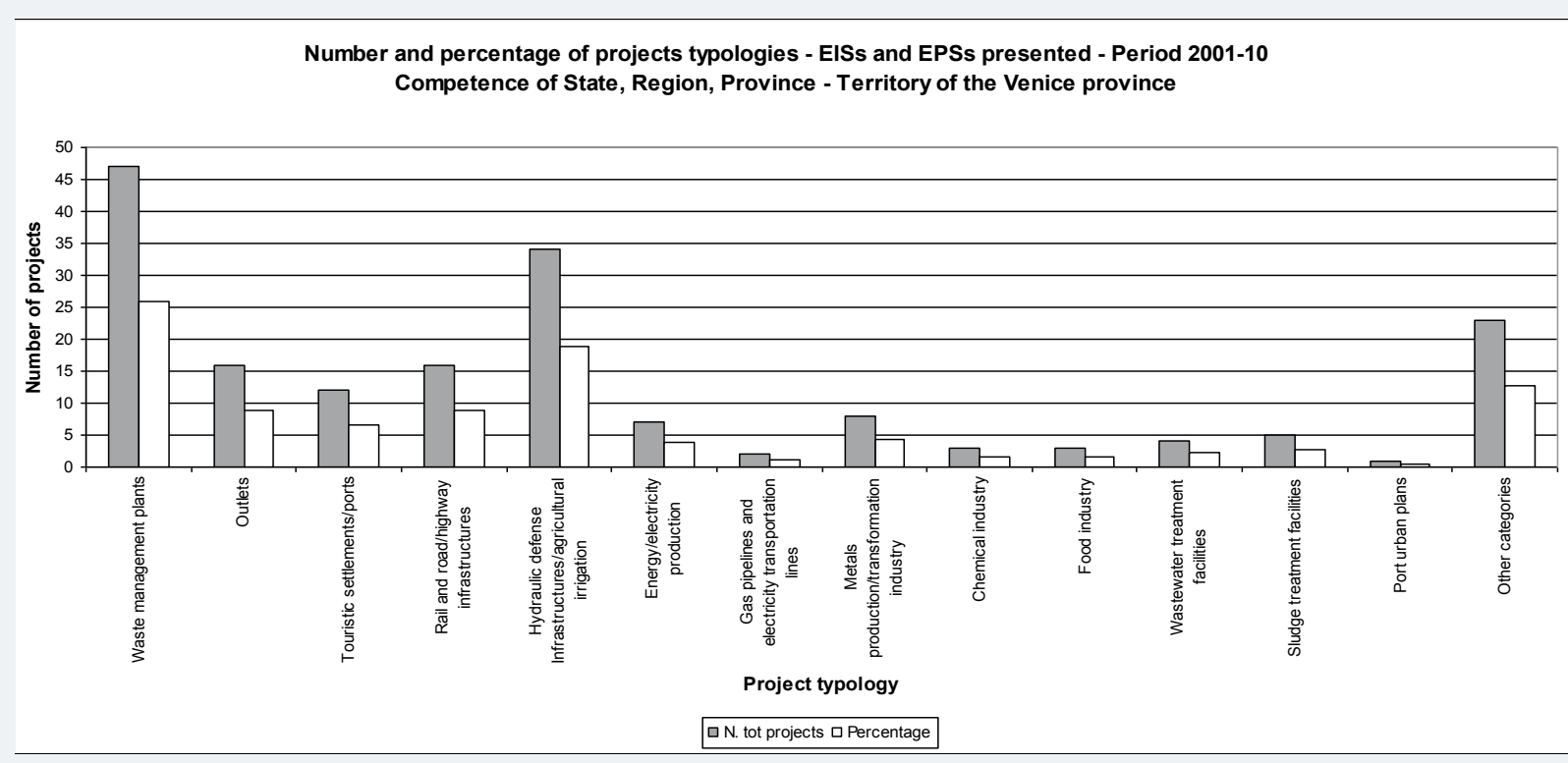

Figure 4: Project typologies - Venice province territory-EIA procedure (screening and ordinary) in the period 2001-10 (Source: data from administrative proceedings Province of Venice 2013).

\section{Number and percentage of projects presented in the Venice province territory referred to competent Authority} Period 2001-10

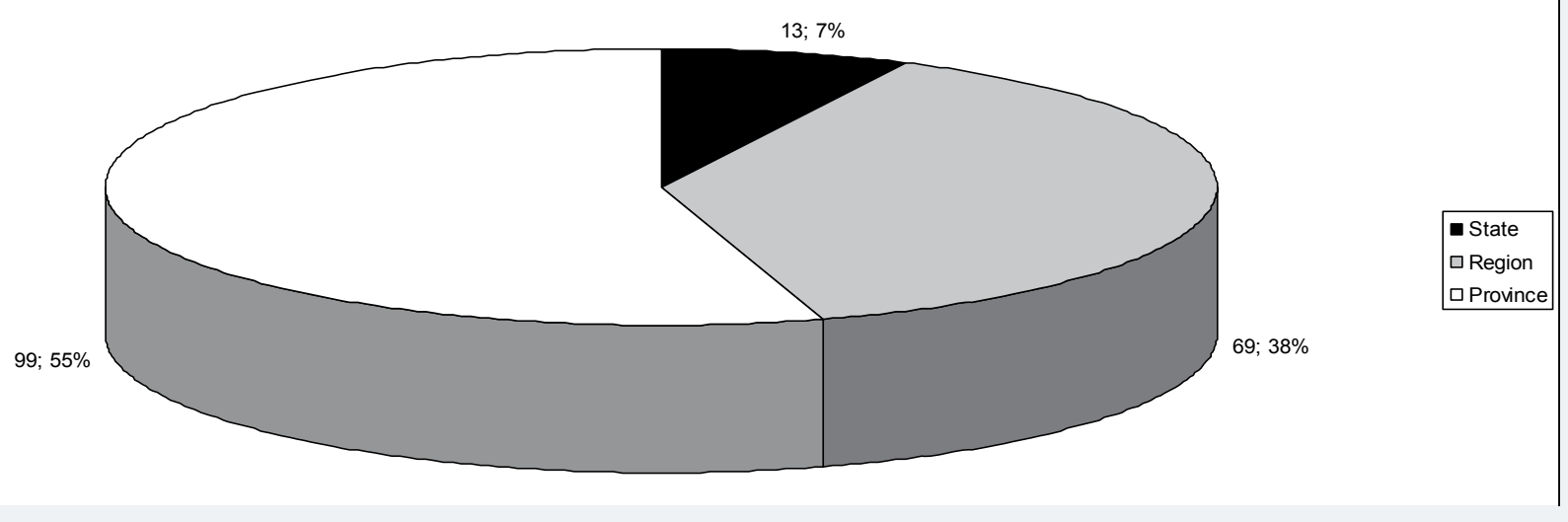

Figure 5: Number and percentage of projects under EIA procedure applied to competent Authorities in the period 2001-10-Venice province territory (Source: administrative proceedings Province of Venice 2013).

can be observed that road-railway infrastructures and electricity production plants are the main project typologies presented in the Province of Venice. As far as road infrastructure is concerned, the Mestre bypass (mainland Venice), completed in 2008 and opened to traffic at the beginning of 2009, appears to be very significant. Projects addressing the chemical industry are concentrated in the industrial estate of Porto Marghera (mainland Venice) and relate to electricity production at 3 power plants situated in different municipalities of the province.

Compared to the national level, the categories of the 69 projects presented at regional level are far more varied. However, nearly half of the projects referred to hydraulic infrastructures, waterways and irrigation infrastructures. Projects relating to the chemical industry are absent, while waste management, sludge/wastewater treatment, metal production/transformation and tourist harbours are new entries when compared to national projects. 
In figure 6 the relative percentages and the number of EIA and screening proceedings for the period 2011-15 for the territory of the Venice province are detailed; in figure 7 the projects are divided in relation to the competent Authority. The detailed data of the project typologies of EIA studies (EIS and EPS) for the territory of the Venice province submitted in the whole considered period 2001-15, with evidence of the competent Authority and with the distinction of the sub-periods (2001-2010 for the recovery and assessment of EIS and EPSs contents and CEs consideration; 2011-15 only for statistical completeness of the study), are reported in table 3.

\section{Consideration of cumulative effects and level of analysis in the case studies}

This study has mainly focused on projects strictly of provincial competence and whose competent Authority is the Province of Venice. A total of n. 99 projects were presented in the period 2001-10. They are divided into the categories reported in figure 8. Official documents with the EIS and Environmental Preliminary Studies

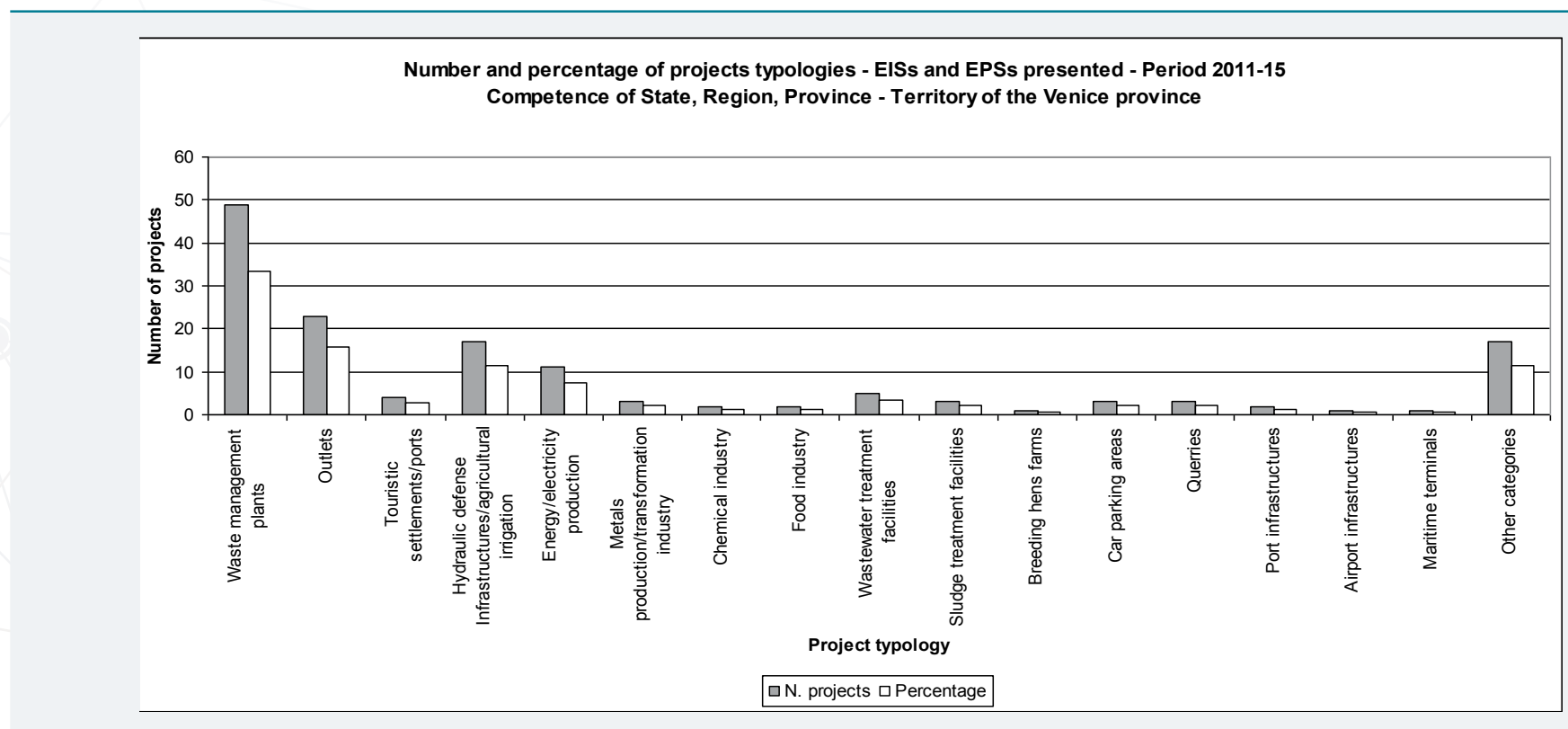

Figure 6: Project typologies-Venice province territory-EIA procedure (screening and ordinary) in the period 2011-15 (Source: administrative proceedings Province of Venice 2016).

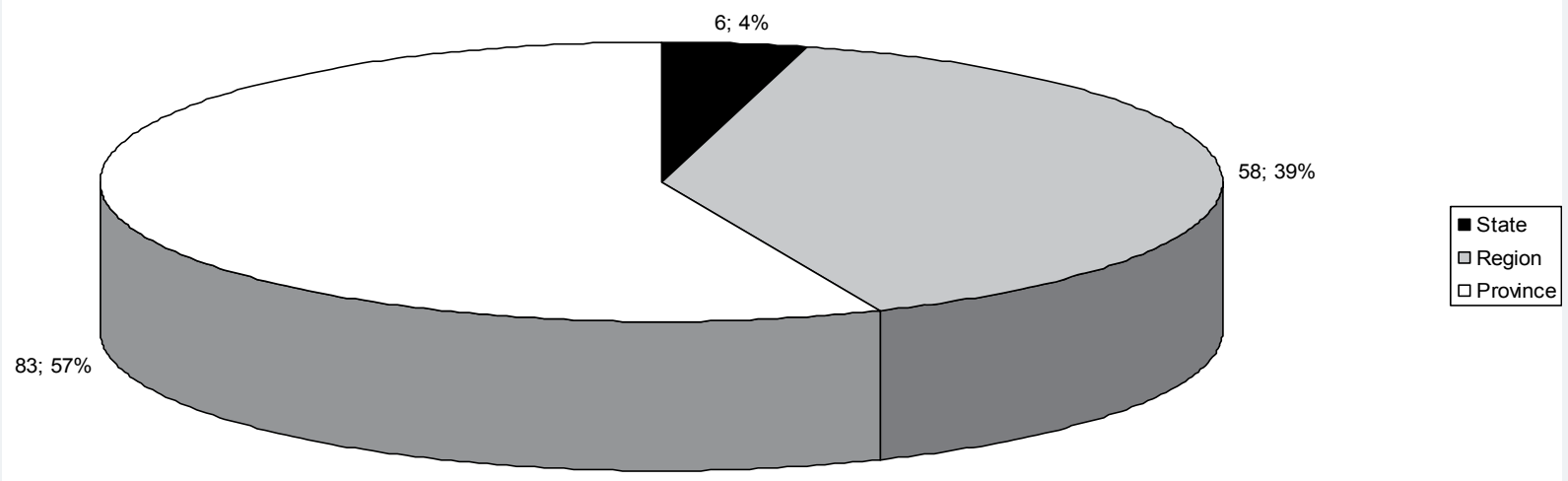

Figure 7: Number and percentage of projects under EIA procedure applied to competent Authorities-period 2011-15-Venice province territory (Source: administrative proceedings Province of Venice 2016). 
Table 3: Typologies of projects and competent Authorities with details in the two periods 2001-10 and 2011-15-Territory of the Venice province (Source: administrative proceedings Province of Venice 2016).

\begin{tabular}{|c|c|c|c|c|c|c|}
\hline \multirow[b]{2}{*}{ Project typologies } & \multicolumn{3}{|c|}{ 2001-10 } & \multicolumn{3}{|c|}{ 2011-15 } \\
\hline & PROVINCE & REGION & STATE & PROVINCE & REGION & STATE \\
\hline Waste management plants & 42 & 5 & & 43 & 6 & \\
\hline Outlets & 16 & & & 23 & & \\
\hline Touristic settlements/ports & 8 & 4 & & 2 & 2 & \\
\hline Rail and road/highway infrastructures & 8 & 4 & 4 & & & \\
\hline Hydraulic defense Infrastructures/agricultural irrigation & & 34 & & & 17 & \\
\hline Energy/electricity production & & 4 & 3 & & 11 & \\
\hline Gas pipelines and electricity transportation lines & & & 2 & & & \\
\hline Metals production/transformation industry & 5 & 3 & & 3 & & \\
\hline Chemical industry & & & 3 & & & 2 \\
\hline Agrofood industry & 3 & & & 2 & & \\
\hline Wastewater treatment facilities & & 4 & & & 5 & \\
\hline Sludge treatment facilities & & 5 & & & 3 & \\
\hline Breeding hen farms & & & & 1 & & \\
\hline Port urban plans & & & 1 & & & \\
\hline Vehicles parking areas & & & & & 3 & \\
\hline Querries & & & & & 3 & \\
\hline Port infrastructures & & & & & & 2 \\
\hline Airport infrastructures & & & & & & 1 \\
\hline Maritime terminals & & & & & & 1 \\
\hline Other categories & 17 & 6 & & 9 & 8 & \\
\hline Total & 99 & 69 & 13 & 83 & 58 & 6 \\
\hline
\end{tabular}

Number of projects for each typology applied to the PROVINCE - Period 2001-2010 Territory of the Venice province

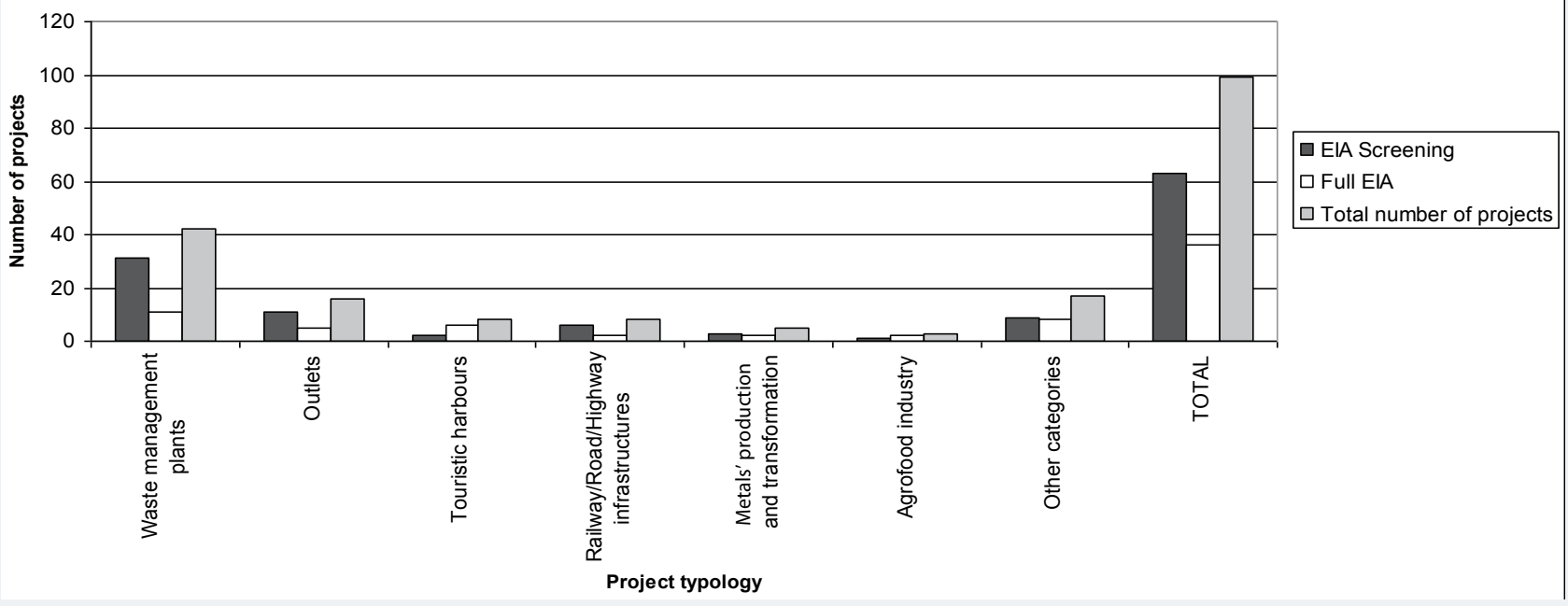

Figure 8: Project typologies analysed in the research and procedure (screening/ordinary)-Provincial competence - Province of Venice, period 2001-2010 (Source: Province of Venice, 2013).

(EPSs) for EIA screening have been made available by the Province's competent office. EPS, as already pointed out, is often erroneously considered by proposers and practitioners alike to be a "reduced or shorter EIS". EPS is actually a pre-requisite of the EIA screening procedure if the proposer is to identify, quantify and assess the potential negative impacts of their own projects in terms of importance and according to the criteria established in the Annex of Part II of Italian Decree n. 152/2006. During this procedure the EIA commission can decide, with sound technical motivation, whether or not the project needs a complete EIS and can request further clarification or it can approve the project imposing prescriptions. 
In the period considered the Venice Province ruled that n. 5 of the EPSs lacked sufficient information and finally imposed a full EIS (complete EIA procedure). It must be pointed out that the screening procedure, according to Directive 97/11/EEC [6], was transposed into Italian legal framework with Italian Decree n. 4/2008 and therefore it had not been applied prior to the above ruling. N. 3 project proposals in the period considered were awarded a negative EIA and were subsequently rejected. Waste management is the activity for which more authorization applications were presented between 2001 and 2010 regarding EIA procedure related to new plants and the refurbishment and modernization of existing ones. In 2010 alone, 19 applications (out of a total of 24) for EIA screening were presented for plants specialising in the recovery of inert waste, non-hazardous waste and material for recycling. Moreover the category of outlet centres is significantly present at the provincial level with $n .16$ projects presented, of which 5 have undergone complete EIA procedures. The tourist harbours, the road/rail infrastructures and metal production/transformation industry have a similar weighting with n. 8, 8 and 5 projects respectively. Finally, the agro-food sector is a new entry in the context of project proposals. The 3 projects presented ( 1 underwent EIA screening while 2 were subjected to the whole EIA procedure) concerned egg poultry farming, drying and milling cereals and the rearing of cattle.

The case studies were selected from a list of 99 projects of provincial competence and for which the available documents were thorough and complete. The initial selection was performed on the full list of projects at the project category level; the following categories appeared to be the most significant: outlet centres, tourist harbours and waste management plants. All three categories revealed a sizeable number of project proposals. In the decade 2001-2010, the EIA screening or complete EIA proceedings relative to the selected categories reached $66 \%$ (for a total of 66 projects) of the total number of projects. A subsequent selection was carried out for each of the categories based on cumulative effects which identified 22 projects (Figures 9,10).

The first issue to be considered is the use of appropriate terminology and whether the same concept of "cumulative effects" is effectively applied and explained in the EIS and/or EPS. CEs is the term most frequently found in scientific literature; it was used and applied in $64 \%$ of the studies analysed for the province of Venice in the period 2001-2010 while 3 cases (14\%) used the following terminology: "combined impacts" or "interacting impacts" or "increasing impacts". In the remaining $22 \%$ of the EISs, the

Number of selected projects for each typology - Provincial competence - 2001-2010

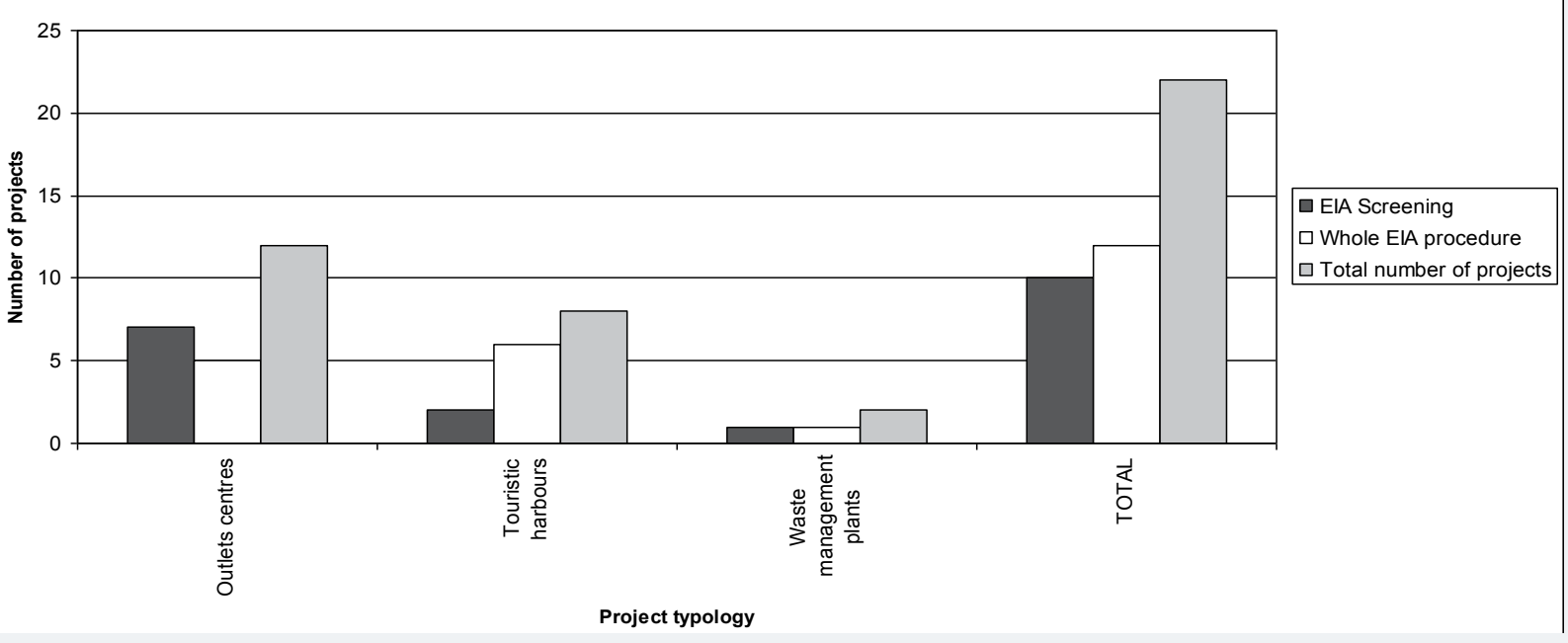

Figure 9: Number of selected projects for the research according to ElA categories and to the procedure (Source: Province of Venice, 2013). 


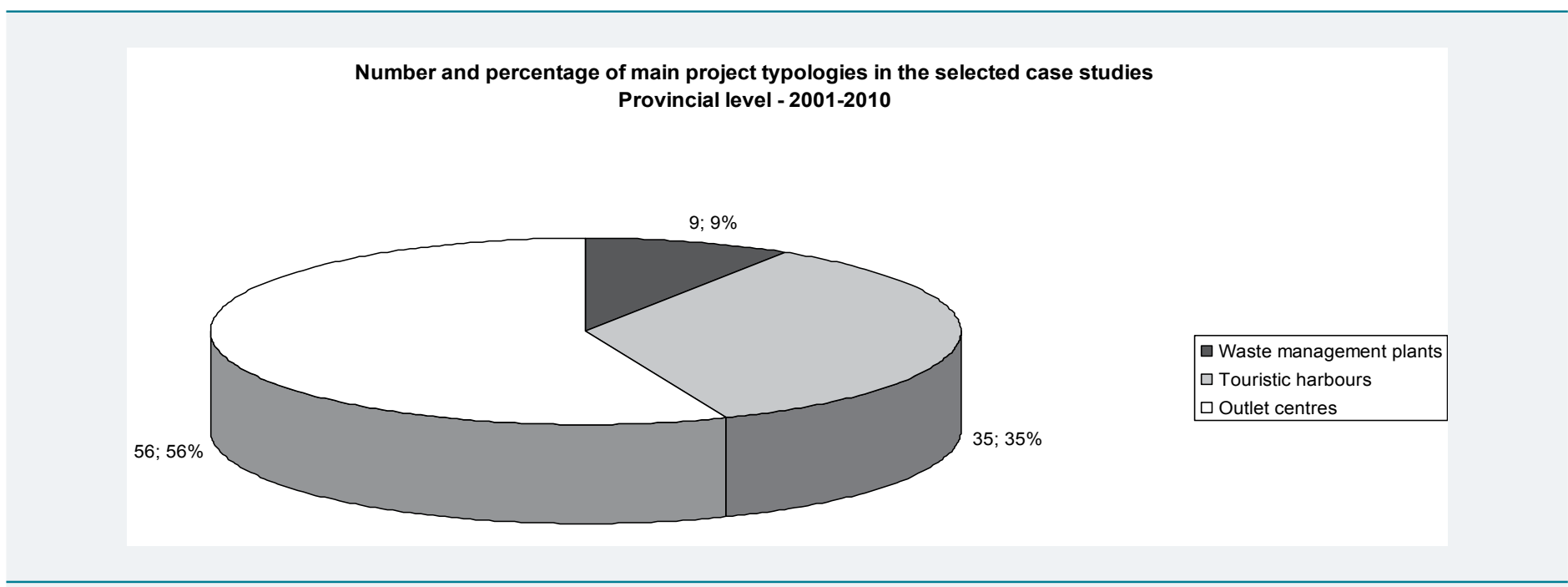

Figure 10: Number and percentage of the project in the selected sample for the reaseach according to EIA categories. Territory of the Venice province. Period: 2001-10 (Source: Province of Venice, 2013).

CEs were not considered at all. The clear definition of CEs was given in only one case for the realization of a new outlet centre in the seaside city of Jesolo. This project is one of the most important among the project sample considered in terms of built surface area $\left(36,381 \mathrm{~m}^{2}\right)$ and the EIS presented appeared to be complete and detailed: the chapter on CEs in this particular project starts by presenting detailed definitions.

Considering the EIS and EPS of the case studies, the emerging general framework is more or less clear. Conversely, from the same terminological point of view, the practitioners who prepared the study were not so clear as far as the CEs' issue was concerned. The only EIS which defined them (outlet centre in Jesolo) presented several definitions due to the lack of standardized terminology at the regulatory level. The sample of 22 projects proved useful at the beginning in providing an indication of how the CEs were developed and considered within the EIS and EPS in the province of Venice. All the EISs and EPSs appeared to be complex documents and the typical structure was set out as follows: planning chapter, project chapter, environmental and impact assessment chapter. Figure 11 reports the results of the analysis performed on EISs and ESPs in the period considered according to their completeness and exhaustivity.

In n. 15 of the EISs (68\%) the documentation included an additional study: an Environmental Incidence Evaluation (EIE), which is performed to assess the potential impacts of a project for the "Nature 2000" network areas, that is all the sensitive sites that require specific prevention measures with the aim to maintain the natural habitats according to Directive 92/43/EEC "Habitat directive" and to Directive 79/409/EEC "Birds' directive" [47]. It can be observed that half of the considered studies indicate the CEs only in the EIE study. This result could be explained by the explicit requirements set out in Directive 92/43/EEC [15] and in the EC guideline [48] concerning the assessment of CEs in protected areas. A problem resulting from the consideration of CEs limited to EIE is that the area of study is restricted solely to the "Nature 2000" areas, excluding other areas where the level of industrial and urban pressure is normally high to very high (as is the case of the province of Venice), and therefore considers the implicitly higher environmental pressure in these areas to be acceptable.

The study performed reflects the problems pointed out by Burris and Canter [26], in particular where the definition of CEs is totally absent or unclear in EIA/SEA regulations; CEs are not properly addressed in the analysed EISs and EPSs, exactly as observed in other realties by Burris and Canter [49]. The negative aspect is that this 


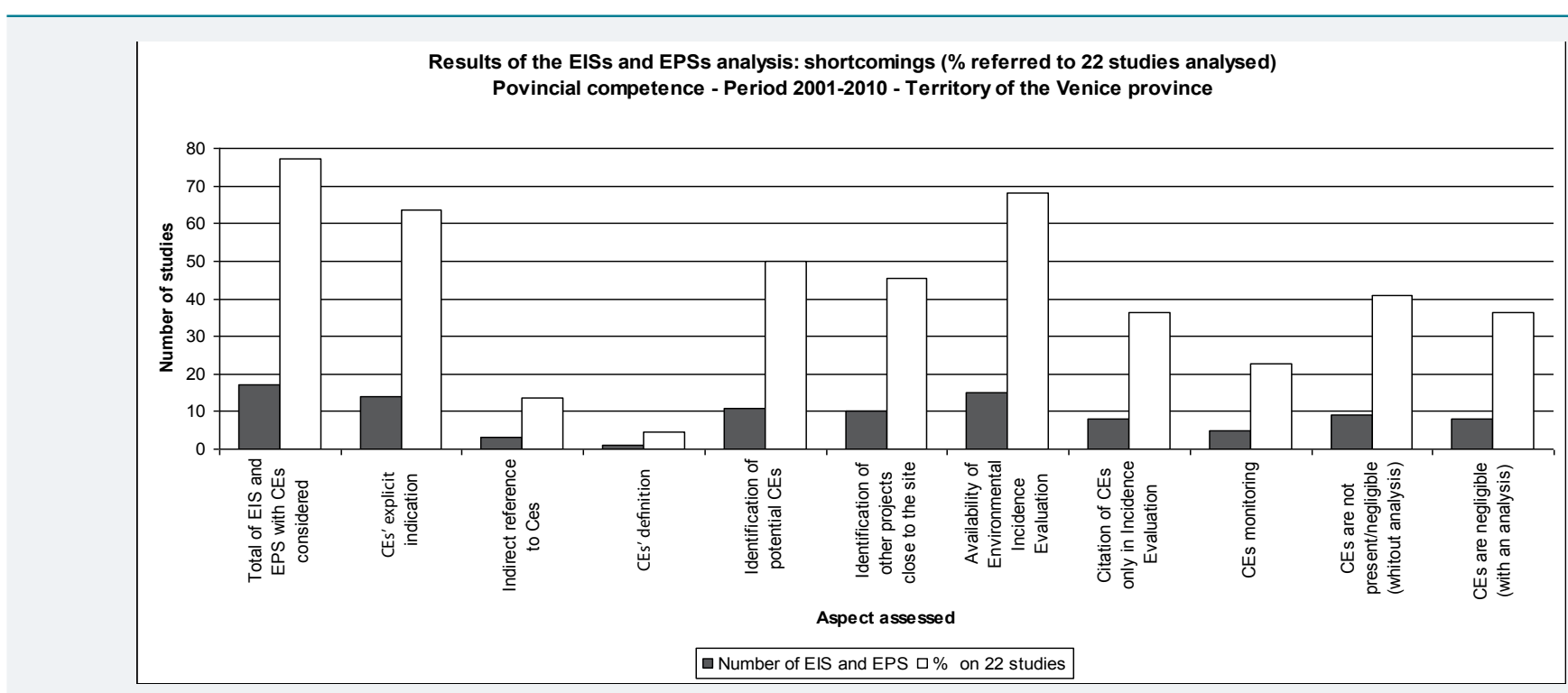

Figure 11: Results of the analysis of EISs and EPSs. Period: 2001-10 (Source: Province of Venice, 2013).

observation was made only in 1997 in the USA. Although EIA practices in Italy began in 1986 with the transposition of Directive 1985/337/EEC, CEs are still currently neither entirely considered nor properly developed (CEs were introduced into the Italian legal framework with the transposition of Directive 97/11/EEC [6], which modified and integrated Directive 1985/337/EEC-and became Italian Decree, n. 152/2006 [45].

This study also revealed the scarce attention generally paid to defining spatial and temporal boundaries, which are fundamental in the initial stages of the CEA procedure [25]. Another shortcoming is that no information at all is given for future actions. Canter [4] points out that CEs are not given detailed attention due to the absence of legal/regulatory requirements; this is Italy's, where the methodological requirements on CEs are somewhat general and open to interpretation in Decree n. 152/2006. According to Burris and Canter [49], CEA should be integrated into the EIA/SEA procedure and significant determinations for CEs should systematically be addressed and properly documented.

\section{Preliminary assessment of cumulative effects: the proposed regional-based approach}

According to Dubè [38] an assessment at regional level with appropriate data from DPSIR model [50] (EEA, 1998) should be carried out for a complete evaluation of the CEs (it is not developed here for space reasons). Figure 12 reports the synthetic flow diagram for the proposed preliminary screening CEA procedure. This procedure could be completed with a project-based (effect-based assessment) as reported by Dubè (2003). CEA requires more time and larger spatial boundaries than those used in the evaluations referred to a single project (project-based approach) as the effects can appear extraneous from the project both in terms of time and space. Therefore a regional approach means this obstacle can be overcome. Considering the two concepts already discussed, defining a complete approach means shifting from the project-CEA (project-based) to the regional-CEA (regional-based). The regional CEA supplies a conceptual framework for the assessment in tune with sustainable development goals. It is of primary importance therefore, to obtain relevant in-field data, gathered locally through state-of-the-art monitoring programmes. Dubè [38], indicates that the CEA process must be supported with environmental data gathered, conformally managed and assessed for the specific problem considered (i.e. scientifically valid data according to a disciplinary sector-based approach). When data are produced by different Authorities and/or by different monitoring programmes, this creates fragmentation, 


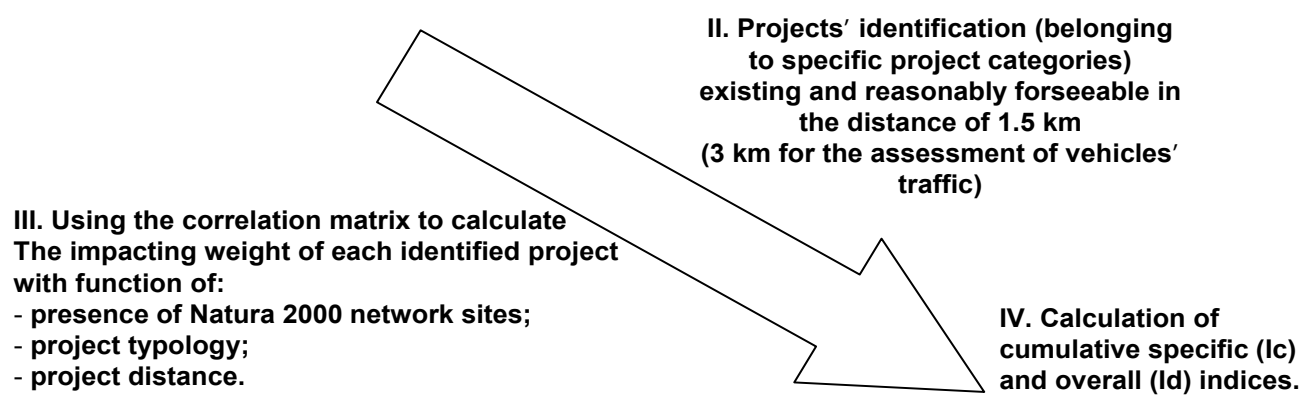

\author{
In case of overtaking of \\ thershold values: \\ preparation of specific \\ integrative, mitigation and \\ compensation mesures, \\ monitoring and control plan
}

Figure 12: Flow diagram of the proposed Cumulative Effects preliminary assessment procedure.

lack of uniformity and a limited access to the data itself. With this aspect in mind, the National and Regional Environmental Agencies play a crucial role in producing and supplying monitoring data.

The proposed approach for CEs' preliminary assessment of waste management plants localization requires firstly a project-based analysis [38] in the considered area in order to recover and use data on the influenced area according to the proposed project/action. Secondly a regional-based analysis will allow the specific assessment. The whole procedure (project-based analysis integrated with regional-based one) is detailed in table 4 according to literature and to the shortcomings identified in the assessed environmental studies. In this procedure protected areas and sensitive sites according to Directive 92/43/EEC [15], for nature conservation (Community Importance Sites) and to Directive 79/409/EEC [47], on bird protection for the identification and protection of special conservation areas must be considered and require specific assessment: the two typologies of areas define the so called "Natura 2000 sites" that constitutes a network of protected areas on the whole territory. GIS tools facilitate the implementation of the assessment procedure.

The criticalities associated with the CEs generated by the three project typologies (outlet centres, waste management plants and tourist harbours), chosen between the considered projects' sample, derive primarily from the fact that the assessment of CEs is rarely considered or is undermined. In most of the studies, the spatial and time variables are not completely developed. Indicatively, the project presented is inserted in a geographical context where there is little or no knowledge of the type of constructions and human actions already present and whether or not they generate impacts which are similar to those assessed for the project under consideration. In this context, many of the effects could appear to be cumulative: these could include the erosion and waterproof of the soil, the modification of animal and vegetal biodiversity and the increased concentration of engine-driven vehicles. Regarding this last problem, CEs were identified in an EPS carried out on the project proposal for a new outlet centre in San Donà di Piave.

As far as tourist harbours are concerned, the boat traffic generated could also have critical repercussions on the intensity of road traffic if traffic volumes are underestimated during certain periods of the year when human activities increase towards, from and around water basins and coastal regions. Of the case studies 
Table 4: Proposed approach for preliminary assessment of Cumulative Effects.

\section{Aspect/phase}

1. Alternatives definition and public participation (information and procedure)

for the proposed project/intervention

2. Strategic, planning activities and Reasonably foreseeable future actions' (RFFAs) identification

\section{CEs' definition}

3. Definition of CEs assessment responsibilities and competence

4. Spatial and temporal boundaries

5. Scoping and baseline conditions

6. Analysis of particularly sensitive areas - Habitat network "Natura 2000" sites

7. CEs' Identification, prediction and assessment of environmental impacts (regional-based CEA)

8. Effect-based (project-based) CEA

9. Impacts' management, mitigation monitoring

\section{Shortcoming/criticalities observed in the environmental studies and comments}

In the case studies, alternatives to the projects have seldom been considered: in most cases the problem is that no one has taken into account whether the project location is in fact really the best for its criticalities in that specific territory. Equally important is the active participation of the citizenship in the decision procedures regarding the authorization of projects subject to EIA and plans subject to SEA. This is particularly important when assessing the alternatives till the first stages of the EIA procedure, as it is fundamental to offer and realise those projects that the population actually needs, by conducting and monitoring them through procedures that are transparent (Directive 2003/35/EC) and respect the principle of subsidiarity.

Usually developed only with existing planning but not considering more recent information. RFFA should encompass the proposed actions not yet approved too. SEA at planning/programming level must define the environmental framework for the interventions that will consequently be realized. CEA at this level can be very useful in a "tiering approach". There are ample reasons for which CEs should be considered at the strategic level. Firstly, the CEs can be revealed on different spatial scales (subregional, regional, national, transnational) and this suggests that the competent Authorities should be responsible for supplying the baseline data and the analysis required by the CE assessment (Cooper and Sheate, 2004). Secondly, mitigation, compensation and monitoring of CEs require a broader outlook than that needed for the assessment of a single project. Moreover, a strategic

approach to CEA can be more proactive in the identification and minimization of potential CEs if these effects have been previously identified during the planning process. At the strategic level, the environmental assessment is currently performed in Italy by means of an environmental report for plans and programmes as established by Directive 2001/42/EC on SEA, transposed into Italian law with Decree n. 152/2006.

The CEs definition must be clarified till the beginning of the study in order to avoid confusion and misunderstanding. The best situation is that where CEA guidelines exist. Some Guides are cited in the text.

Responsabilities and competences are clear if laws/regulations are clear. Litigations are evident when procedure are not clear and this is the case of CEs: not explicit and clear approaches are defined and required to the project proponent.

The methodologies should be the same used for the CE's prediction and assessment. A project proposal that does not have specific time and spatial guidelines on which to base the assessment of the CEs, definitely restricts these dimensions to a narrow, site-specific area which is closely limited to its immediate surroundings. For this reason, the projects that can be considered generators of impacts, and therefore can be assessed together, are really very limited. In many cases, the problem of who is actually responsible for planning and conducting the CEA is evident. On the one hand, the proposer is clearly fully aware of the potential impacts arising from his project, on the other, the public Authority/ies should be familiar with the environmental issues within and around the interested territory.

The description of environmental baseline conditions is often the most useful content when identifying existing projects and those of future realization in the areas bordering a considered project's site. It can also contribute to identifying CEs. In the scoping phase only half of the studies presented potential CEs. Generally CEs have been unsatisfactorily developed.

CEs' assessment is a requirement of Directive 92/43/EEC. It is important that this assessment is not limited only to this obligation as often appears in the practice. Investigating the CEs during the Environmental Incidence Evaluation (EIE) procedure for "Natura 2000" sites is surely positive if we consider that the Natura 2000 network sites are those areas of a territory that have greater biodiversity, are biologically and ecologically valuable with regard to species, populations and communities. Yet, this also poses limitations as it protects vast areas and quantities of natural resources and prevents the ecological functionality of the environments that are not encompassed in the protected areas and which have a high degree of human presence and transformation. If attention is directed mainly to the more valuable areas, there is the risk that the rest of the territory is subject to increasingly unlimited, uncontrolled degradation.

This stage normally is not developed. It must be linked to SEA procedure.

Here the regional based methodology of Lombardia Region (2010) is proposed and applied with modifications. The identification, prediction and assessment of environmental impacts is the most difficult stage, especially when having to produce a quantitative estimate of effects subsequent to the qualitative phase. The difficulty and the uncertainty when assessing CEs can favour, an underestimation of the effects unless appropriate analytic methodologies are applied. In various cases, the detailed and more satisfactory examination of CEs was the result of an explicit request from the EIA Commission that the documents be integrated. According to the single projects. It is the normal procedure that do not consider what happens around.

The mitigation measures proposed in most of the studies deal with the direct impacts of the projects. The exclusion of the CEs assessment means that the implementation of mitigation and monitoring measures of these impacts are not considered necessary. On the other hand this is a compulsory issue.

examined, the potential criticality regarding the Venice lagoon is of particular interest. These criticalities concern the construction of new tourist harbours (current and in the near term) in close proximity to the sea mouth around the Lido. At a distance of $6 \mathrm{~km} 4$ new tourist harbour projects have already been approved ( 3 new and 1 enlargement). These harbours will increase the number of boats/ships (most of them $<18 \mathrm{~m}$ in length) by 1440 units.

The issue of cumulative effects has triggered a significant number of discussions which are encompassed in the general scientific field of EIA/SEA and in specific scientific sectors. From the investigation carried out, only $36 \%$ of the case studies actually went on to produce an in-depth analysis of likely CEs. The reasons for this are numerous but mainly attributable to the lack of guide-lines which favours an accurate 
assessment of the CEs as well as the proposer's decision not to carry out in-depth research as it can highlight one or more aspects of the project's incompatibility with the environment in which it is supposed to be inserted.

\section{Assessment of environmental cumulative effects in the case studies}

In the following the application of the preliminary assessment procedure from Lombardia region (2010) modified and applied to the context of the province of Venice is developed. This procedure appears to be a regional-based approach to CEs' assessment according to Dubè [38]; this evaluation is obtained by considering: the proposed project, other RAFFAs that can interfere with it, the monitoring of the state of the environment and the control of the pressure sources within the defined spatialtemporal domain. In table 5 the specific values for each project category are reported in the correlation matrix for the distance range of 0-500 $\mathrm{m}$ from the new project. When weighing up the indicators (soil, induced traffic, induced emissions and groundwater were added as they were not present in the original methodology); estimates were made as to how much a mean representative plant for each of the typologies could influence each of the indicators. Subsequently, the comparison with the attributed weights using the basic method for the other indicators was considered. The same approach as that applied to waste management plants was carried out for two other stressors: tourist harbours and large outlet structures (highlighted in grey).

From the qualitative point of view, it is necessary to explain the characteristics of the additional indicators (highlighted in grey in table 5):

- Soil: Identifies the entity of soil consumption and surface impermeability of a human intervention/project, to point out potential hydraulic problems in the examined area;

- Induced traffic: identifies the potential movement of engine-driven vehicles entering and exiting the project site; it could exacerbate the inadequacy of the existing road structures or, an excessive concentration of engine-driven vehicles (cars/trucks or boats/ships), which must be considered; this indicator considers the potential damage that traffic can cause to the structures close to the vehicle circulation flows (for example the effects of waves and swell on building foundations produced by boat traffic in the Venice Lagoon);

\begin{tabular}{|c|c|c|c|c|c|c|c|c|c|c|c|c|c|c|c|c|c|c|c|c|c|c|c|}
\hline & & \multicolumn{22}{|c|}{ Anthropogenic pressure indicators,u } \\
\hline & & PM10 & Nox & $\mathrm{SO}_{2}$ & co & $\mathrm{CO}_{2}$ & cov & $\mathrm{CH}_{4}$ & $\mathrm{NH}_{3}$ & $\mathrm{~N}_{2} \mathrm{O}$ & Odors & $\begin{array}{c}\mathrm{O}_{2 \text { dassolued }} \\
\mathrm{BOO}_{5}\end{array}$ & COD & 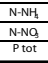 & Inorg. Pollutio & Org, Pollution & Noise & Vibrations & Non ioniz. Rad & \begin{tabular}{|c} 
Soil \\
consumption
\end{tabular} & Induced traffif & $\begin{array}{l}\text { Induced } \\
\text { emissions }\end{array}$ & $\begin{array}{l}\text { Groundwater } \\
\text { extraction }\end{array}$ \\
\hline \multirow{17}{*}{ 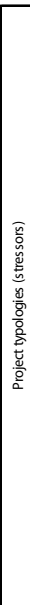 } & Quarries & 12 & 8 & 8 & 8 & 8 & 0 & 0 & 0 & $\frac{26}{4}$ & 0 & & 0 & 0 & $\begin{array}{ll}0 \\
\end{array}$ & 0 & 8 & 8 & 0 & 12 & 4 & & \\
\hline & Landolls & 8 & 8 & 8 & 8 & 8 & 8 & 8 & 8 & 4 & 12 & 0 & 0 & 0 & 0 & 0 & 8 & 4 & 0 & 12 & 8 & 8 & 0 \\
\hline & Outlets & 8 & ${ }^{4}$ & 4 & 4 & 8 & 4 & 0 & 4 & ${ }^{4}$ & 0 & 0 & 0 & 0 & 0 & 0 & 0 & 4 & 0 & 12 & 12 & 12 & 0 \\
\hline & $\begin{array}{c}\text { Waste } \\
\text { treatment } \\
\text { plants }\end{array}$ & 8 & 8 & 8 & 8 & 8 & 8 & 0 & 8 & 8 & 8 & 0 & 0 & 0 & 0 & 0 & 4 & 0 & 0 & 8 & 4 & 8 & 0 \\
\hline & Incinerators & 12 & 8 & 8 & 8 & 12 & 8 & 0 & 4 & 8 & 4 & 0 & 0 & 0 & 0 & 0 & 4 & 0 & 4 & 8 & 12 & 12 & 4 \\
\hline & $\begin{array}{c}\text { Composting } \\
\text { plants }\end{array}$ & 4 & 4 & 4 & 4 & 4 & 4 & 0 & 4 & 4 & 8 & 0 & 0 & 0 & 4 & 4 & 4 & 0 & 0 & 8 & 8 & 8 & 0 \\
\hline & \begin{tabular}{|c|} 
Wastewater \\
Tretment \\
Plants \\
\end{tabular} & 4 & 4 & 4 & 4 & 4 & 4 & 4 & 4 & 4 & 4 & 16 & 8 & 24 & 4 & 4 & 4 & 0 & 0 & 8 & 0 & 0 & 0 \\
\hline & \begin{tabular}{|c|} 
Cattle breedin \\
settlements
\end{tabular} & 4 & 4 & 4 & 4 & 4 & 4 & 4 & 4 & 4 & 8 & 16 & 8 & 24 & 4 & 8 & 4 & 0 & 0 & 4 & 4 & 4 & 4 \\
\hline & $\begin{array}{c}\text { Energy } \\
\text { activities }\end{array}$ & 12 & 8 & 8 & 8 & 8 & 8 & 8 & 8 & 8 & 4 & 0 & 4 & 12 & 4 & 4 & 8 & 4 & 4 & 8 & 8 & 8 & 8 \\
\hline & Metal industro & 12 & 8 & 8 & 8 & 8 & 8 & 8 & 8 & 8 & 4 & 0 & 4 & 12 & 4 & 4 & 8 & 4 & 0 & 8 & 8 & 8 & 8 \\
\hline & \begin{tabular}{|c|c|} 
Mineral \\
Industry \\
\end{tabular} & 8 & 8 & 8 & 8 & 8 & 8 & 0 & 4 & 4 & 4 & 0 & 4 & 12 & 4 & 4 & 8 & 4 & 0 & 8 & 8 & 8 & 8 \\
\hline & 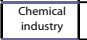 & 8 & 8 & 8 & 4 & 8 & 8 & 4 & 8 & 8 & 4 & 0 & 4 & 12 & 4 & 4 & 8 & 4 & 0 & 8 & 4 & 8 & 8 \\
\hline & Other activitief & 8 & 8 & 8 & 8 & 8 & 8 & 8 & 8 & 8 & 4 & 0 & 4 & 12 & 4 & 4 & 8 & 4 & 0 & 4 & 4 & 4 & 4 \\
\hline & \begin{tabular}{c|} 
Roadd \\
infrastruct.
\end{tabular} & 8 & 8 & 8 & 8 & 8 & 8 & 0 & 8 & 0 & 4 & 0 & 0 & 0 & 0 & 0 & 8 & 0 & 0 & 8 & 12 & 12 & 0 \\
\hline & Airports & 12 & 8 & 8 & 8 & 8 & 8 & 0 & 8 & 8 & 0 & 0 & 0 & 0 & 0 & 0 & 12 & 4 & 8 & 12 & 12 & 12 & 0 \\
\hline & 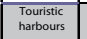 & 8 & 8 & 4 & 4 & 4 & 4 & 0 & 0 & 4 & 0 & 8 & 0 & 0 & 0 & 0 & 8 & 0 & 0 & 4 & 12 & 12 & 0 \\
\hline & $\begin{array}{c}\text { Commercial } \\
\text { harbours }\end{array}$ & 12 & 12 & 8 & 8 & 12 & 8 & 0 & 8 & 8 & 0 & 8 & 0 & 0 & 0 & 0 & 12 & 4 & 0 & 12 & 12 & 12 & 0 \\
\hline
\end{tabular}


- induced emissions: are directly correlated to induced traffic, but they depend on the type and power of engine-driven vehicles; for example in a waste management plant the number of vehicles entering is inferior to those entering a large outlet structure (lower traffic flows), however, the effect in terms of polluting chemical species and dusts (induced emissions) could be significant and should be considered and carefully analysed;

- Groundwater extraction: the excessive, widespread withdrawal of groundwater (free and confined groundwater) can reduce the piezometric level or a lowering of the free level layer; usually the most significant withdrawal is performed by industrial sites for process cooling water.

Scores have been attributed on a scale of 0-12 (minimum and maximum impact) in order to obtain a homogeneous evaluation with the Lombardia region method and according to the nature of the pressure/parameters and their intensity. The scores were calculated by authors simulating the "pairwise expert judgement" [51]. Roughly speaking, three catergories of impacts can be identified: low 0-4; medium 5-8; high 9-12. For the projects encompassed in the other two previously mentioned distance ranges of $500-100 \mathrm{~m}$ and $1000-1500 \mathrm{~m}$, the method requires a progressive halving of values. The index values are respectively $1 / 2$ and $1 / 4$ of the reference ones (see Table 4). If the project falls within the boundaries of a site belonging to the "Nature 2000" network (babitat protection sites), then it appears useful in the assessment scale to double the weight values for all the pertinent ranges, that is for area 1, area 2 and area 3. Moreover, it is appropriate to maintain "Induced traffic" and "Induced emissions" indicators within a maximum of $3000 \mathrm{~m}$ from the project. This measure is, in particular, precautionary albeit based on the fact that these two factors present both localized and diffused impacts which should not be overlooked. The weight of the cumulative effects, resulting from different projects localized in the same area and their interaction with a proposed new project, depends on:

- $\quad$ typology of project (Table 2);

- distance from the new project based on the ranges: 0-500 m, 500-1000 m and 1000-1500 $\mathrm{m}$ for all the indicators excluding "Induced traffic" and "Induced emissions" for which the $0-3000 \mathrm{~m}$ range is applied;

- $\quad$ presence in the area of Nature 2000 network sites (Sites of Community Importance-Directive 92/43/EEC[15] and Special Protection Areas-Directive 79/409/EEC[47]);

- $\quad$ Correlation values between projects and indicators (Table 5), weighted for proximity to the new project.

At this point, indices $I_{C}$ and $I_{D}$ must be determined for the examined project, also taking into account whether or not the numerical thresholds have been exceeded as reported in table 6. Modifications made to the original method in the simulation performed made it possible to obtain a maximum cumulative score (1940) which was $32 \%$ higher than the original (1476). For this reason, it was decided to increase the threshold and the percentage values of the two indices $I_{C}$ and $I_{D}$. Table 7 , shows the indices $I_{d}$ and $I_{c}$ calculated for the tourist harbours in this area. The calculation refers to the proposed methodology for CEA with some modifications based on the typologies of the chosen projects. The CEs are also considered with the two indices.

The presented approach in case of waste management plants or of Integrated Prevention Pollution and Control [17], plants can help to identify potential impacts and to estimate the potential environmental damage that must be defined to decide the amount of the financial warranties required for the operative phase of this plants as 


\begin{tabular}{|l|c|c|}
\hline \multicolumn{1}{|c|}{ Table 6: Numerical threshold for $\mathrm{I}_{\mathrm{c}}$ and $\mathrm{I}_{\mathrm{d}}$. } \\
\hline \multicolumn{1}{|c|}{ Indices } & $\mathrm{I}_{\mathrm{c}}$ & $\mathrm{I}_{\mathrm{D}}$ \\
\hline Original method & $\mathrm{C}=60$ & $\mathrm{D}=500$ \\
\hline Modified method & $\mathrm{C}=79$ & $\mathrm{D}=660$ \\
\hline
\end{tabular}

Table 7: Calculation of $I_{D}$ and $I_{D}$ in the area of the sea mouth for touristic harbours - Venice lagoon.

\begin{tabular}{|c|c|c|c|c|c|c|c|c|c|c|c|c|c|}
\hline \multirow[b]{2}{*}{ Projects (stressors) } & \multicolumn{12}{|c|}{ Anthropogenic pressure indicators $\left(u_{j}\right)$} & \\
\hline & $\mathbf{P M}_{10}$ & $\mathrm{NO}_{\mathrm{x}}$ & $\mathrm{SO}_{2}$ & CO & $\mathrm{CO}_{2}$ & VOC & $\mathrm{N}_{2} \mathrm{O}$ & $\begin{array}{c}\mathrm{O}_{2} \text { Dissolved } \\
\mathrm{BOD}_{5}\end{array}$ & Noise & $\begin{array}{l}\text { Soil } \\
\text { cons. }\end{array}$ & $\begin{array}{l}\text { Induced } \\
\text { Traffic }\end{array}$ & $\begin{array}{l}\text { Induced } \\
\text { emissions }\end{array}$ & \multirow{5}{*}{$\begin{array}{c}\text { Cumulative } \\
\text { impact index I }\end{array}$} \\
\hline Case 1 - New project & 16 & 16 & 8 & 8 & 8 & 8 & 8 & 16 & 16 & 8 & 24 & 24 & \\
\hline $\begin{array}{l}\text { Case } 2(0-500 \mathrm{~m})-\mathrm{New} \\
\text { project }\end{array}$ & 16 & 16 & 8 & 8 & 8 & 8 & 8 & 16 & 16 & 8 & 24 & 24 & \\
\hline $\begin{array}{l}\text { Case } 3(0-500 \mathrm{~m})- \\
\text { Existing harbour }\end{array}$ & 16 & 16 & 8 & 8 & 8 & 8 & 8 & 16 & 16 & 8 & 24 & 24 & \\
\hline $\begin{array}{l}\text { Case } 4(0-3000 \mathrm{~m}) \text { - } \\
\text { New project }\end{array}$ & 0 & 0 & 0 & 0 & 0 & 0 & 0 & 0 & 0 & 0 & 24 & 24 & \\
\hline $\begin{array}{l}\text { Cumulative specific } \\
\text { impact index } I_{c}\end{array}$ & 48 & 48 & 24 & 24 & 24 & 24 & 24 & 48 & 48 & 24 & 96 & 96 & 528 \\
\hline
\end{tabular}

stated by art. 14 ("financial security") of Directive 2004/35/EC [18], on environmental liability. The first problem is the identification of environmental components potentially impacted in ordinary and not ordinary conditions (for example accidents, fires, explosions, etc.) and then to try to assess the potential damage that must be covered by the financial warranty (insurance, bank deposit, etc.) stipulated in favour of the Authority responsible for the authorisation procedure. This means that an economic evaluation of the potential environmental damages must be done. Normally it must be distinguished if the restoration of the resource is possible or not and therefore the remedying cost or the cost of a surrogate resource must be calculated. It is clear that this is an issue of the estimation professionals but the correct starting point must consider the identification of potential impact and their entity in terms of value and extention of the effects; this assessment is a duty of environmental professionals that need specific and appropriate tools. The proposed approach tries to do this unless the subjectivity of the measuring scales applied.

\section{Conclusions}

Human interventions and projects cause impacts on the neighbouring environment first for the simple fact to exist and in added/synergistic way with similar interventions and/or activities with similar pressure factors. In highly urbanized and populated areas, Cumulative Effect Assessment (CEA) appears necessary to decide very quickly if an intervention is feasible and particularly in environmental and territorial planning through the Strategic Environmental Assessment (SEA)/Environmental Impact Asseessment (EIA) screening procedure. The analysis of Cumulative Effects (CEs) can bring significant benefits as it identifies problems which in any case require attention [52]. For the CE assessment to be effective the competent Authority needs to be able to supply the proposers of new projects subject to EIA screening or in full EIA procedures with sound tools for the EIS/EPS assessment. These same tools should be used by the Authorities responsible for the Strategic Environmental Assessment (SEA) procedure for the plans and programmes where the single interventions are encompassed. The availability of updated GIS systems concerning the quality of the environments considered, and the pressure sources in the same territory, is crucial for assessing the extent of the effects produced by the proposed intervention and for the CEA of new interventions in the same area. In this way, additive or synergic effects can be considered and evaluated: it is evident that if single projects with little or no effects are considered together, and in relation to existing pressures in a defined area, they can produce a significant impact (an example is the problem of soil consumption and soil waterproofing interventions).

In the territory of the Venice province (north-east Italy, Veneto region) in the period 2001-15 n. 328 environmental studies (preliminary or definitive) have been 
presented to competent Authorities (of which 19 to the State, 127 to the Veneto Region and 182 to the Venice Province). All the Environmental Impact Studies (EISs) and Environmental Preliminary Studies (EPSs), referring to the this territory officially applied to competent Authorities in the period 2001-2010, have been analysed with focus on the identification and assessment of CEs, the projects considered and analysed for this purpose comprise a total of n. 181 EIA screening and ordinary procedures; the remaining 147 projects in the period 2011-15 (for a total of 328) have been considered only for statistical reason to an update assessment of project typologies in the same territory but were not analysed for CEs.

The set of Environmental Impact Studies (EISs) and Environmental Preliminary Studies (EPSs), relative to the territory of the Venice province, analysed in this study, have made it possible to better understand and define the assessment procedure for CEs in the decade 2001-2010 and which of these presents cause for concern. A preliminary proposal of Cumulative Effects Assessment (CEA) procedure has been presented and discussed, starting from those proposed by [14,25], integrated with the regional approach [38], and with a specific approach for CEs [42] based on the application of Geographical Information Systems (GIS), specifically created for the assessment of waste management plants.

In the documents of the sample of EISs and EPSs analysed in this study similar critical issues have been identified. The CEA framework in the case studies appears to be rather poor. Although there are only 5 (22\%) EISs and EPSs where the Cumulative Effects have been completely overlooked, the other studies clearly restrict the area being investigated more or less to the area of the projected interventions. A total of $41 \%$ of the studies either omits CEs or, where they are present, they are considered negligible, without supporting any analysis. The 36\% of the studies takes CEs into account only in the environmental incidence evaluation (EIE, for Natura 2000 sites); with this approach the CEs cannot be estimated and assessed sufficiently to allow for a better understanding of how the areas neighbouring the project will develop. It has been confirmed that CEs are much more developed when there is a specific requirement in the regulation in force [26].

The methodology proposed by Lombardia Region [42], was modified and applied to a selected set of studies in the province of Venice. It allows a regional-based analysis for a preliminary Cumulative Effects Assessment, where systemized and standardized data from regional monitoring are necessary. This procedure must be completed with a project-based analysis on the single projects. To take care of potential interference, planning tools must be analyzed on a GIS base to understand which can be the Reasonably Forseeable Future Actions (RFFAs); at the same time the system must allow to define the spatial and temporal boundaries and support the impact prediction/ assessment. In European legislation Nature 2000 sites [15], must be considered but sufficient attention must be paid to already stressed areas [48], to avoid not acceptable impacts.

Moreover Directive 2011/92/EU on EIA observes that the threshold values to undergo EIA procedure for a plant typology must be defined by a case-by-case process. It is evident that these values can be not fixed but varying as function of the local and regional conditions according to the real pressure on the considered territory/area. Therefore the proposed approach appears useful for this purpose too.

The identification of potential environmental damages and their estimation appear of main importance also to assess the entity of the financial warranties required for the release of the operative permits by competent Authorities for waste management and Integrated Pollution Prevention and Control (IPPC) plants as stated at European level by 
art. 14 of European Directive 2004/35/EC [18], on environmental liability. This aspect appears of general interest as far as the environmental liability issue is considered all over the world by Environmental Authorities and by Insurance companies when dealing with industrial sites with significant potential environmental impacts.

\section{Acknowledgements}

The authors wish to thank: the personnel of the Province of Venice involved in the EIA procedure, Ms. Marisa Severi of the Ca' Foscari University of Venice, Italy for the English revision of the paper, and above all Prof. Gabriele Zanetto of the Ca' Foscari University of Venice who followed the MSc thesis which gave rise to this research. Prof. G. Zanetto unfortunately passed away in April 2013. He will be remembered for his humanity, professional competence and teaching abilities. His memory will remain in our hearts.

\section{References}

1. Spaling H, Smit B. Cumulative environmental change: conceptual frameworks, evaluation approaches and institutional perspectives. Environmental Management. 1993; 17: 587-600. Ref.: https://goo.gl/aUzfb3

2. Cocklin C, Parker S, Hay J. Notes on cumulative environmental change: concepts and issues. Journal of Environmental Management. 1992; 35: 31-49. Ref.: https://goo.gl/SGn14Q

3. Contant C, Wiggins L. Defining and analyzing cumulative environmental impacts. Environmental Impact Assessment Review. 1991; 11: 297 -309. Ref.: https://goo.gl/aAUmgh

4. Canter LW. Environmental impact assessment. McGraw-Hill Book Company, London,. Second Edition. 1996.

5. Directive $85 / 337 /$ EEC of $27 / 06 / 1985$. Environmental Impact Assessment of public and private projects. EU OJ n. L 175 of 20/07/1985.

6. Directive $97 / 11 /$ EC of 3/03/1997. Modifications of Directive 85/337/EEC on EIA. EU OJ n. L 73 of 14/03/1997.

7. Directive $2003 / 35 / E C$ of $26 / 05 / 2003$. Public participation in respect of the drawing up of certain plans and programmes relating to the environment and amending with regard to public participation and access to justice. EU OJ n. L 156 del 25/06/2003.

8. Directive $2011 / 92 / E U$ of $13 / 12 / 2011$ on the assessment of the effects of certain public and private projects on the environment, EU OJ L 26 of 28/01/2012.

9. Directive 2014/52/EU of 16/04/2014 amending Directive 2011/92/EU on the assessment of the effects of certain public and private projects on the environment, EU OJ L 124 of 25/04/2014.

10. US-NEPA, 1969. The national environmental policy act of 1969. I. 91-190, 42 u.s.c. 4321-4347, January 1,1970 , as amended by I. 94-52, July 3,1975 , I. 94-83, August 9, 1975, and I. 97-258, § 4(b), 1982.

11. Zanetto G, Ostoich M, Wolf A, Pastore A, Frasson G. La valutazione degli impatti cumulativi nelle trasformazioni territoriali: studio campione in provincia di Venezia. Rivista Geografica Italiana-RGIItalian Geographic Review (in Italian). 2014; 121: 119-139.

12. Zanetto $G$, Ostoich $M$, Wolf $A$. La valutazione degli impatti cumulativi: studio campione in provincia di Venezia in "Le categorie geografiche di Giorgio Spinelli - Ambiente, Energia, Geopolitica, Turismo" (in the memory of Giorgio Spinelli) in Italian, Pàtron Editore, Bologna. 2014.

13. Smit B, Spaling H. Methods for cumulative effects assessment. Environmental Impact Assessment Review.1995 15: 81-106. Ref.: https://goo.gl/G1vNRP

14. Cooper LM, Sheate WR. Cumulative effects assessment: a review of UK environmental impact statements. Environmental Impact Assessment Review. 2002; 22: 415-439 Ref.: https://goo.gl/sZzXKG

15. Directive 92/43/EEC of 21/05/1992. Wild Natural Habitat Conservation. EU OJ n. L 206 of 22/07/1992

16. Atkinson SF, Canter LW. Assessing the cumulative effects of projects using Geographic Information Systems. Environmental Impact Assessment Rev. 2011; 31: 457-464. Ref.: https://goo.gl/nj9uQq 
17. Directive 2010/75/EU, Industrial emissions (Integrated Pollution Prevention and Control), EU OJ L 334 of $17 / 12 / 2010$

18. Directive $2004 / 35 / E C$, of $21 / 04 / 2004$ on environmental liability with regard to the prevention and remedying of environmental damage, EU OJ L 143 of 30/04/2004.

19. Regulation $\mathrm{n}$. $761 / 2001 / \mathrm{EC}$ concerning the voluntary participation by organisation in a community eco-management and audit scheme (EMAS). EC OJ n. L 114/1 of 24/04/2001, 2001.

20. ISO 14001. Environmental Management Systems-Use requirements. ISO. 2004.

21. US-CEQ-Council of Environmental Quality. Regulations for implementing the procedural provisions of the National Policy Act. 40 CFR 1508, 1 July, Washington, DC. 1996.

22. Hegmann G, Cocklin C, Creasey R, Dupuis S, Kennedy A. et al. Cumulative effects assessment practitioners guide, prepared by Axys Environmental Consulting and CEA Working Group for the Canadian Environmental Assessment Agency. 1999.

23. Cooper LM, Sheate WR. Integrating cumulative effects assessment into UK strategic planning: implications of the European Union SEA directive. Impact Assessment and Project Appraisal. 2004; 22: 5-16. Ref.: https://goo.gl/m3fVGk

24. Rumrill JN, Canter LW. Addressing future actions in cumulative effects assessment. Project Appraisal. 1997; 12: 207-218. Ref.: https://goo.gl/Fst91E

25. Rumrill JN, Canter LW. Cumulative air quality effects assessment. Federal Facilities Environmental Journal, John Wiley \& Sons Inc. 2000; 11: 19-38. Ref.: https://goo.gl/oWggvj

26. Burris RK, Canter LW. A practitioner survey of cumulative impact assessment. Impact Assessment. 1997; 15: 181-194. Ref.: https://goo.gl/GB93hE

27. Gunn J, Noble BF. Conceptual and methodological challenges to integrating SEA and cumulative effects assessment. Environmental Impact Assessment Review. 2011 31: 154-160. Ref.: https://goo.gl/EtLKwJ

28. Baxter W, Ross WA, Spaling H. Improving the practice of cumulative effects assessment in Canada. Impact Assessment and Project Appraisal. 2001; 19: 253-262. Ref.: https://goo.gl/j9X1f7

29. Wärnbäck A, Hilding-Ryedevik T. Cumulative effets in Swedish EIA practice - Difficulties and obstacles. Environmental Impact Assessment Review. 2009; 29: 107-105. Ref.: https://goo.gl/JpAxrE

30. Partidario MR. Significance and the future of SEA. International Workshop on SEA, Tokyo, 26-27 th November 1998.

31. Partidario MR. Elements of a SEA framework-improving the added-value of SEA. Environmental Assessment Review. 2000; 20: 647-663. Ref.: https://goo.gl/sWJq76

32. US-CEQ-Council of Environmental Quality. Cumulative effects analysis: handbook for NEPA Practitioners. Washington, DC: US CEQ. 1994.

33. US-CEQ-Council of Environmental Quality. Considering cumulative effects under the National Environmental Policy Act. Executive Office of the President. Washington, D.C. 1997; 49-57.

34. Walker LJ, Johnston J. Guidelines for the assessment of indirect and cumulative impacts as well as impact interactions. EC DG XI. Environment, Nuclear safety \& Civil Protection. 1999. Ref.: https://goo.gl/FqE44y

35. Swor T, Canter LW. Promoting environmental sustainability via expert elicitation process. Environmental Impact Assessment Review. 2011; 31: 506-514. Ref.: https://goo.gl/cXNtwY

36. Hegmann G, Yarranton GA. Alchemy to reason: effective use of cumulative effects assessment in resource management. Environmental Impact Assessment Review. 2011; 31: 484-490 Ref.: https://goo.gl/f1RpdQ

37. Canter LW, Atkinson SF. Multiple uses of indicators and indices in cumulative effects assessment and management. Environmental Impact Assessment Review. 2011; 31: 491-501. Ref.: https://goo.gl/EKUSZq

38. Dubé MG. Cumulative effect assessment in Canada: a regional framework for aquatic ecosystems Environmental Impact Assessment Review. 2003; 23: 723-745. Ref.: https://goo.gl/wTupo7

39. Province of Venice. The provincial urban waste management plan. Venezia. 2008. 
40. Bondesan A, Meneghel M. Geomorphological digital map of the Province of Venice. Venice. 2004.

41. Province of Venice. Geological units of the Province of Venice. Venezia. 2009.

42. Lombardia Region. Deliberation of the Regional Board of 10/02/2010 n. 8/11317. Method for EIA screening procedure for waste management plants (in Italian). Lombardia Region Official Journal Suppl. n. 8-26/02/2010, 2010. [SITO, accessed July 2014].

43. ISPRA Italian Chief Institute for Environmental Protection. Nature map system, accessed July 2014

44. US-EPA-Environmental Protection Agency, 1998. Guidelines for ecological risk assessment, Washington, DC. 2014.

45. Italian Legislative Decree 3/04/2006 n. 152. Regulation for environment protection, Ordinary Suppl. Italian OJ n. 96 14/04/2006.

46. Veneto Region, Regional Law 26/03/1999, n. 10. Disciplina dei contenuti e delle procedure di Valutazione di Impatto Ambientale (EIA regulation - in Italian). Regional Official Journal n. 29, 1999.

47. Directive 79/409/EEC del 2/04/1979. Birds' protection. EU OJ n. I 103 del 25/04/1979.

48. European Commission, 2001. Assessment of plans and projects significantly affecting natura 2000 sites, Luxembourg: office for official publications of the european comunities. 2014.

49. Burris RK, Canter LW. Cumulative impacts are not properly addressed in environmental assessments. Environmental Impact Assessment Review. 1997; 17: 5-18. Ref.: https://goo.gl/sUAHEi

50. EEA European Environment Agency. Europe's Environment. The second assessment. Copenhagen. 1998.

51. Saaty TL. The Analytic Hierarchy Process. McGraw-Hill. 1980.

52. Therivel R, Ross B. Cumulative effects assessment: does scale matter? Environmental Impact Assessment Review. 2007; 27: 365-385. Ref.: https://goo.gl/3BQaQe

53. Directive 96/61/EC, Integrated Pollution Prevention and Control (IPPC), EU OJ L 257 of 10/10/1996.

54. Directive 2001/42/EC of 27/06/2001. Assessment of the effects of plans and programmes on the environment. EU OJ n. L 197 of 21/07/2001. 